\title{
Scanning electrochemical microscopy and its potential for studying biofilms and antimicrobial coatings
}

\author{
Giada Caniglia $^{1} \cdot$ Christine Kranz $^{1}$
}

Received: 17 May 2020 /Revised: 8 June 2020 / Accepted: 19 June 2020 / Published online: 21 July 2020

(C) The Author(s) 2020

\begin{abstract}
Biofilms are known to be well-organized microbial communities embedded in an extracellular polymeric matrix, which supplies bacterial protection against external stressors. Biofilms are widespread and diverse, and despite the considerable large number of publications and efforts reported regarding composition, structure and cell-to-cell communication within biofilms in the last decades, the mechanisms of biofilm formation, the interaction and communication between bacteria are still not fully understood. This knowledge is required to understand why biofilms form and how we can combat them or how we can take advantage of these sessile communities, e.g. in biofuel cells. Therefore, in situ and real-time monitoring of nutrients, metabolites and quorum sensing molecules is of high importance, which may help to fill that knowledge gap. This review focuses on the potential of scanning electrochemical microscopy (SECM) as a versatile method for in situ studies providing temporal and lateral resolution in order to elucidate cell-to-cell communication, microbial metabolism and antimicrobial impact, e.g. of antimicrobial coatings through the study of electrochemical active molecules. Given the complexity and diversity of biofilms, challenges and limitations will be also discussed.
\end{abstract}

Keywords Scanning electrochemical microscopy $\cdot$ Biofilm $\cdot$ Bacteria $\cdot$ Quorum sensing $\cdot$ Antimicrobial

\section{Introduction}

The term biofilm was used in technical and environmental microbiology already for a long time to describe bacterial sessile aggregates as a cause of biofouling [1]; however, Costerton et al. [2] first introduced the term biofilm in biomedical research, studying the proteomic of Pseudomonas aeruginosa microcolonies. The authors described them as an interconnected and well-organized community of bacteria, able to stick to both biotic and abiotic surfaces, exhibiting increased antimicrobial resistance in comparison with planktonic cell cultures. It is estimated that bacteria in biofilms become up to 1000 times more resistant to antimicrobial agents [3]. Due to the elevated resilience, biofilms affect our societies in many ways ranging from health-related issues,

Published in the topical collection featuring Female Role Models in Analytical Chemistry.

Christine Kranz

christine.kranz@uni-ulm.de

1 Institute of Analytical and Bioanalytical Chemistry, Ulm University, Albert-Einstein-Allee, 11, 89081 Ulm, Germany such as contamination in medical devices, e.g. urinary catheters [4], cardiovascular devices [5] and orthopaedic prosthetics [6], in food industries [7], agriculture [8] and biocorrosion and microfouling in sewer pipes, shipping industries, etc. [9-11]. Biofilms are the cause of about $65 \%$ of chronic diseases in humans [12]. For example, Staphylococcus aureus is able to colonize the upper respiratory tracts and cause chronic diseases such as rhinitis and bronchial asthma [13]. Salmonella [14], Pseudomonas [15], Bacillus [16] and Listeria [17] are biofilm-forming food pathogens, causing the food industry enormous costs each year [18]. Xylella fastidiosa, a plant pathogenic bacterial species, which causes huge economic losses in crops (grapevine, citrus, etc.) mostly in the Americas, has reached Europe causing severe damage to olive-growing regions in Italy [19]. X. fastidiosa is known to obstruct the water pathways within more than 100 different plants after irreversible adhesion to the xylem surface and formation of biofilms. Not all biofilms are harmful, and biofilms are used in microbial fuel cell (MFC) technology, converting chemical energy from water-based organic matter into electricity. Besides, some bacterial strains contribute to bioremediation processes, e.g. oil-consuming bacteria [20] and microbes that can uptake heavy metals [21]. 
In order to design new and effective strategies to prevent biofilm formation, understand antimicrobial resistance, improve performances of MFCs, etc., it is important to understand the biochemical processes during the microbial colonization and the biofilm formation [22]. Biofilm formation is a complex multistage process [2] which starts with the adhesion of the bacteria at a surface. After an irreversible attachment to the surface, followed by cell division and proliferation, microbes start to secrete extracellular polymeric substances (EPSs) composed of proteins, polysaccharides and nucleic acids. EPS is a viscous matrix that promotes the cohesion of cells and provides physical protection to bacteria [23, 24]. During the colonization, bacteria release products, such as metabolites, which are related to the development and reproductive activities of the microbes. Identifying and mapping their concentration gradients is important to understand biofilm behaviour. Given the heterogeneity of biofilms [25], metabolite secretion of cells may be different depending on the location in the biofilm, due to the internal gradients of e.g. nutrients, oxygen and $\mathrm{pH}$ [26].

One of the most important mechanisms coordinating the biofilm formation is quorum sensing (QS) [27]. Biofilms exhibit advanced cell-to-cell communication governed by the secretion of small specific molecules, which regulates an interaction among cells through induced gene expression. The nature of QS molecules depends on the type of bacteria. As shown in Fig. 1, peptide-based QS molecules are usually expressed by Gram-positive species, such as Enterococcus [22], while acyl-homoserine lactone (AHL) derivates are characteristic of Gram-negative bacteria, like Vibrio [28] and Pseudomonas [29]. These molecules can change the gene transcription profile, activating or repressing specific QScontrolled genes [30]. Gene mutation, during the first stages of biofilm formation, regulates the biogenesis of the flagella called type I pili, which are not only essential to the first interaction with the surface but also contribute to the pathogenicity of the bacteria $[31,32]$. Inhibiting the secretion of such molecules is one strategy to avoid the formation of biofilms. However, this requires an understanding of how bacteria communicate, and as a diverse group of chemical species is produced, their identification is important. Figure 1 represents characteristic QS molecules for Gram-positive and Gramnegative bacteria.

Peptide-based QS molecule

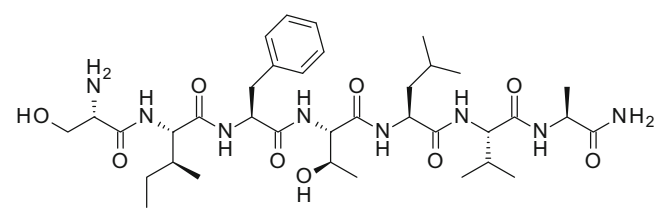

Enterococcus faecalis
In order to understand multistage processes involved in biofilm formation (as depicted in Fig. 2a), a multitude of strategies has been developed and many different methods are employed, ranging from advanced microscopic and spectroscopic techniques $[33,34]$ to mass spectrometry $[35,36]$ and proteomic methods [37, 38]. The interested reader is directed to recent reviews on methodical approaches for more information [39-41].

The adhesion of bacteria at surfaces, which is the initial step of biofilm formation, has been intensively studied via atomic force microscopy (AFM) [42] for Gram-negative and Gram-positive bacteria including e.g. Xylella fastidiosa [43]. An AFM-derived method termed "single-cell AFM force spectroscopy" (SCFM) [44] allows mapping of adhesion properties at the single cell level, i.e. the study of the cellcell and cell-surface interactions in different environments and types of surfaces [45-47]. The role of microbial adhesins and bacterial pili, as well as their molecular binding mechanism, has been studied by SCFM [48, 49].

Real-time advanced optical techniques such as confocal laser scanning microscopy (CLSM) contributed to the knowledge of the spatial structure of biofilms with single-cell-level resolution and the quantitative determination of structural parameters, such as roughness, biovolume and thickness using highly specific fluorescent probes [50]. The combination of CLSM with fluorescence in situ hybridization (FISH) allowed the spatial identification of bacteria in mixed communities such as multibacterial oral biofilms [51, 52]. Coupling CLSM with the fluorescence lectin-binding analysis (FLBA) has opened up new possibilities for in situ determination of glycoconjugate and its distribution via $3 \mathrm{D}$ imaging, which is highly interesting as glycoconjugates are one of the species present in the EPS produced by bacteria during biofilm formation [53-55]. Time-based monitoring of EPS compounds was also demonstrated with non-destructive, label-free techniques that do not require e.g. fluorophores, such as infrared attenuated total reflection (IR-ATR) spectroscopy [56, 57] or Raman microscopy [58, 59]. IR-ATR spectroscopy not only provides biochemical and physiological information of the biofilm but also allows monitoring how biofilms evolve over time by the changes of the IR-ATR fingerprint region [60]. Besides biofilm composition, also the antimicrobial effects of biofilm inhibitors have been studied via IR-ATR [56].

\section{Acyl homoserine lactones}

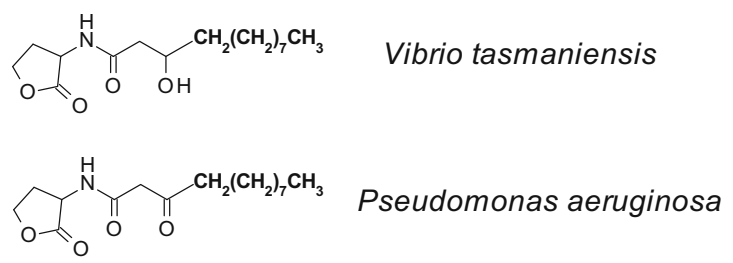

Fig. 1 Characteristic QS molecules and their chemical structures 


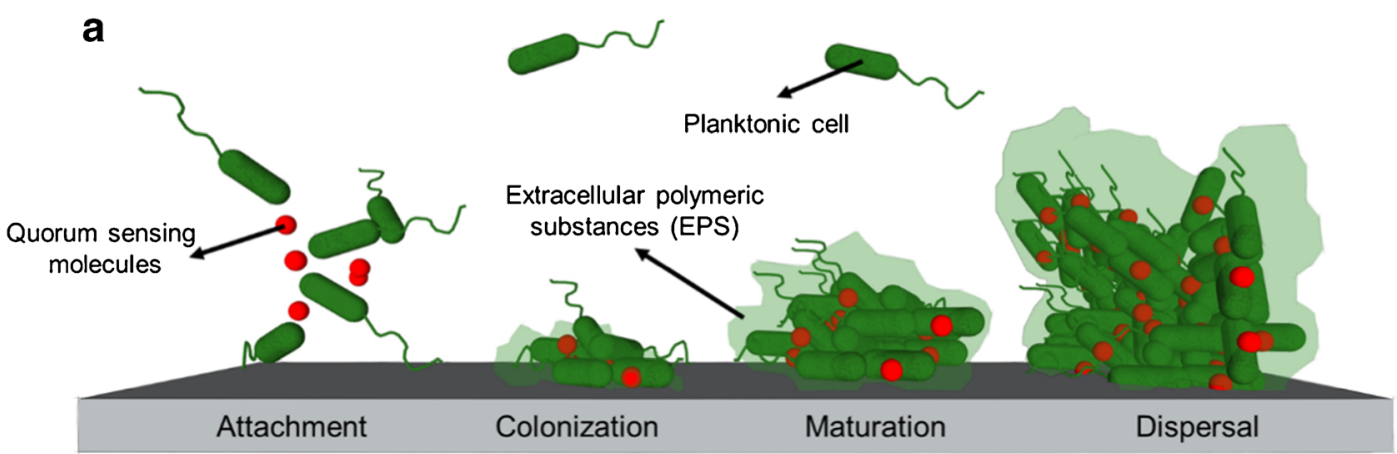

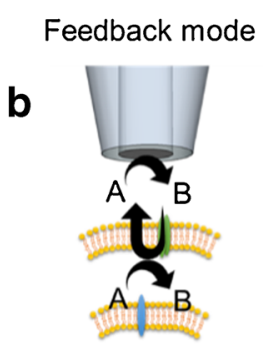

Molecules absorption

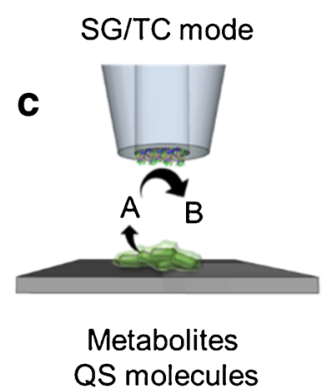

Metabolites

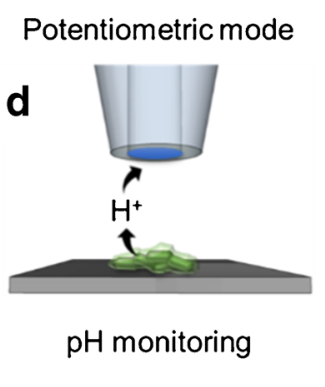

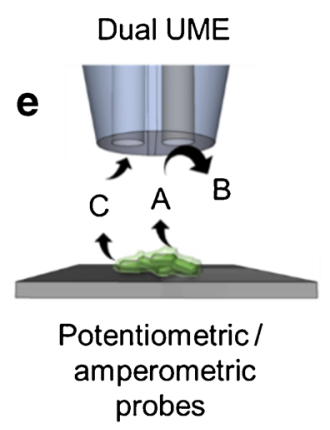

Dual UME

Fig. 2 (a) Schematic of multistage biofilm formation. (b-f) SECM modes used to study biofilms

Although intensive research efforts have been dedicated towards understanding the formation and the growth of biofilms, to date, there are still open questions such as "which mechanism governs the formation and stability of biofilms?" This review is focused on microelectrochemical approaches, mainly scanning electrochemical microscopy (SECM) and its potential for studying key chemical parameters that are influencing biofilm formation and growth.

\section{Microelectrochemistry}

Electrochemical methods, such as potentiometry, voltammetry or electrochemical impedance spectroscopy (EIS), have been used in biofilm research, for example, in respect to non-destructive monitoring of bacterial communities [61], the investigation of redox-active bacteria such as Shewanella oneidensis MR-1 [62] and Geobacter sulfurreducens [63], the effect of electrode material to minimize biofouling [64] and for insight into quorum sensing [65]. For example, electrochemical approaches have been used to study long-distance electron transport at Geobacter sulfurreducens that can use electron acceptors residing outside the cell for respiration [63]. In particular, microelectrochemistry and SECM are attractive methods for real-time investigation of redox-active small molecules with micron-scale resolution. Studies on effects of polarized substrates and extracellular electron transfer play a significant role in biofuel cell research. In respect to microelectrochemical studies and SECM investigations on biofilm formation and cellular communication, the effect of substrate potential or the effect of depletion of molecules such as oxygen has been little addressed in the literature.

Electrochemical microsensors and microbiosensors for the analysis of biofilms have been employed for more than 30 years [66] to study micron-scale chemical gradients and metabolism in microbial communities. The advantage of using microsensors is associated with the improved sensitivity and selectivity. Depending on the molecule of interest, various types of microsensors have been developed, some are also commercially available. The most common potentiometric microsensors are ion-selective microelectrodes using liquidion-exchange membranes for i.e. $\mathrm{pH}$ [67], ammonium and nitrite [68]. Oxygen, nitrogen-containing molecules and hydrogen peroxide, which are correlated with respiration, nitrogen cycles and oxidative stress of bacteria, respectively, are also mapped with amperometric micro(bio)sensors [69, 70]. Another interesting approach in terms of miniaturized electrochemical sensing is related to integrated circuits using complementary metal-oxide-semiconductor (CMOS) technology. For example, spatially resolved imaging of three electroactive phenazine metabolites of Pseudomonas aeruginosa PA14 biofilms was obtained using a high-density array with 1824 gold integrated electrodes multiplexed to 38 parallel output channels [71].

To date, only a few reviews are available, addressing, among other topics, the versatility and advantages of SECM in biofilm research $[72,73]$. This review will give an overview on microelectrochemical approaches, focusing on SECM to study important factors, such as nutrients, metabolites, ion concentrations profiles and QS at bacterial communities, and 
also addressing current challenges and possible limitations. For detailed information on SECM, the readers are directed towards some excellent reviews, providing a detailed description of imaging modes and applications as well as some fundamental aspects of SECM [72-76].

\section{Scanning electrochemical microscopy}

In SECM, miniaturized electrodes (currently electrodes with radii ranging from $25 \mu \mathrm{m}$ down to several $\mathrm{nm}$ ) [77, 78] are used as SECM tips to map information of the sample surface, while the tip is moved across the sample surface. In dependence of the SECM mode, the surface morphology and the tip size, the current response may depend on both topography and electrochemical activity [74].To date, biofilm studies have been performed with conventional SECM, where the SECM tip is positioned via recording $z$-distance vs. current curves (approach curves) and then either perform stationary measurements or scan the SECM tip in a constant height across the sample surface. In feedback mode SECM (Fig. 2b), electron transfer (ET) reactions within bacterial cells can be investigated by using a hydrophilic redox mediator, which can cross the outer cell membrane and behave as an electron acceptor in the respiratory chain of the microbial cell [79]. In this context, the mediator regenerates in the periplasm of the cell and an increase of the current response is registered. The rate constant of the mediator regeneration, knowing its concentration and formal potential, can provide valuable information about the electron transport mechanism in the respiration chain.

Gradients of key parameters such as $\mathrm{pH}$, oxygen, redox potential, virulence factors, metabolites and ions evolve at biofilms, controlled by diffusional processes through the 3D architecture of the EPS matrix [80]. Besides, it is known that bacterial metabolism, associated with the production of acidic by-products, leads to $\mathrm{pH}$ changes within the biofilm, which may differ from external $\mathrm{pH}$ values. Substrate generation/tip collection (SG/TC) (Fig. 2c) belongs to most relevant SECM modes for studying bacteria and biofilms, since redox species released from the cells are collected by the SECM probe, whose electrochemical response reveals the spatial and temporal concentration profile of the species. Concentration profiles and kinetics of target molecules, such as metabolites, QS molecules or drugs consumed, which are relevant in the different stages of the biofilm formation, have been demonstrated in SG/TC mode [81, 82]. The potentiometric mode of SECM allows to study label-free changes in a concentration of molecules or species that are not electroactive by using ionselective microelectrodes (see Fig. 2d). Although pH changes are frequently studied with fluorescence probes as spatiotemporal resolution can be achieved [83, 84], potentiometric probes for $\mathrm{pH}$ measurements such as $\mathrm{Sb} / \mathrm{SbO}_{2}$ [85], $\mathrm{Ir} / \mathrm{IrO}{ }_{x}$ [86], polyaniline [87] and ultramicroelectrodes (UME) and carbon-based $\mathrm{pH}$ microsensors [88] are attractive as no labelling is required. Also, dual ultramicroelectrodes (Fig. 2e), which allow both potentiometric and amperometric measurements to obtain morphological information and $\mathrm{pH}$ profiles with the same probe, have been shown. Oxygen consumption (Fig. 2f) can be studied using a Clark UME [89], which consists of a platinum ultramicroelectrode with a silver ring, acting as a reference/counter electrode.

\section{Applications in biofilm studies}

While electrochemical methods have been used in microbial studies for quite some time, SECM has only been employed more frequently in microbial research within the last decade. Gram-positive and Gram-negative bacteria such as Staphylococcus aureus [90], Rhodobacter sphaeroides [79], Salmonella typhimurium [91], Pseudomonas aeruginosa [92, 93], Vibrio fischeri [94], Streptococcus gordonii [95] and Escherichia coli $[82,96-98]$ have been investigated with SECM. Earlier SECM studies were mainly focused on mapping oxygen consumption of microbial cells [99]. Also, the transmembrane charge transfer in Rhodobacter sphaeroides using hydrophilic and hydrophobic redox mediators in SECM feedback mode has been investigated [79]. The study revealed that hydrophobic redox species can penetrate both the outer cell membrane and the cytoplasmatic membrane, while hydrophilic mediator only crosses the outer membrane.

In recent years, applications of SECM regarding biofilms have been focused on the study of key parameters such as electroactive metabolites, QS molecules, consumption of nutrients and oxygen, ion concentrations and $\mathrm{pH}$ (Fig. 3).

Hydrogen peroxide $\left(\mathrm{H}_{2} \mathrm{O}_{2}\right)$ is produced by several aerobic bacteria associated with the human body such as Streptococcus, Pneumococcus and Lactobacillus strains. $\mathrm{H}_{2} \mathrm{O}_{2}$ is responsible, among other reactive oxygen species (ROS), for oxidative stress and plays a significant role in inflammation processes. How microbial $\mathrm{H}_{2} \mathrm{O}_{2}$ influences hostmicrobial interactions is, to date, still not fully understood [100]. SECM was used to detect $\mathrm{H}_{2} \mathrm{O}_{2}$ at biofilms to study glucose metabolism and catalase activity during the formation of Streptococcus gordonii [95] and Vibrio fischeri [94] biofilms. To date, most studies used spectrophotometric methods for $\mathrm{H}_{2} \mathrm{O}_{2}$ determination using a peroxidase assay following a protocol by Gilliland [101]. However, $\mathrm{H}_{2} \mathrm{O}_{2}$ can be detected electrochemically at either bare microelectrodes, using enzyme-based microsensors [102], or electrocatalytically modified microelectrodes such as Prussian blue [103] or platinum black [104], which allow to map $\mathrm{H}_{2} \mathrm{O}_{2}$ concentrations down to the nanomolar range.

Liu et al. [81] used the SG/TC mode (Fig. 2c) to map $\mathrm{H}_{2} \mathrm{O}_{2}$ concentration above the Gram-positive bacterium Streptococcus gordonii and co-cultured biofilms of S. gordonii and Aggregatibacter actinomycetemcomitans, a 


\section{SECM probe}

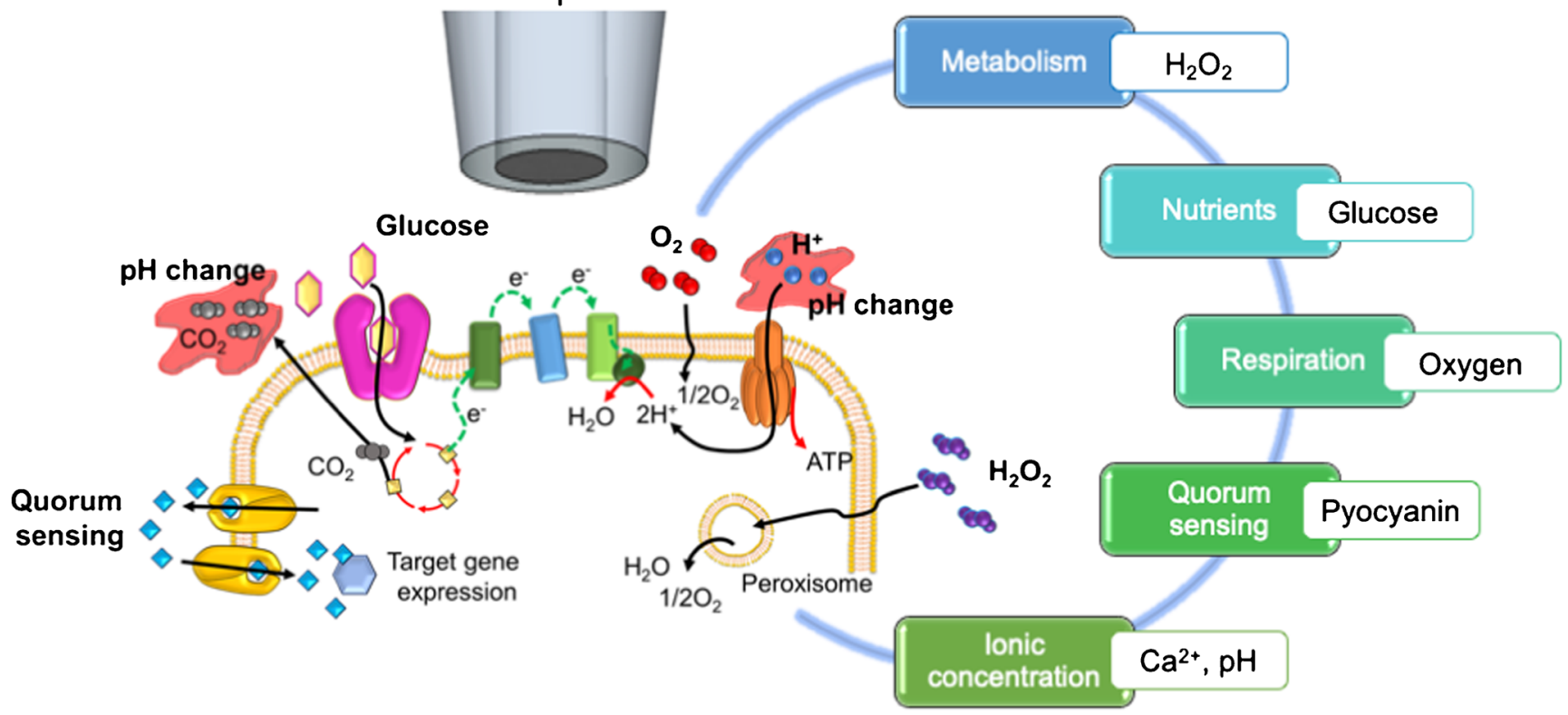

Fig. 3 Representative parameters in biofilm research investigated with SECM

Gram-negative bacterium. S. gordonii converts sugars into lactic acid, producing $\mathrm{H}_{2} \mathrm{O}_{2}$ in the presence of $\mathrm{O}_{2}$. A higher $\mathrm{H}_{2} \mathrm{O}_{2}$ level was detected in case of $S$. gordonii biofilm, compared to its planktonic counterpart. The authors could also show that A. actinomycetemcomitans co-cultured with $S$. gordonii reduces $\mathrm{H}_{2} \mathrm{O}_{2}$ levels due to the presence of a protein (KatA) of the catalysed enzyme family. Line scans clearly revealed a decrease in $\mathrm{H}_{2} \mathrm{O}_{2}$ levels above the A. actinomycetemcomitans spot in comparison to increased levels above a KatA-deficient $A$. actinomycetemcomitans mutant. The recorded $\mathrm{H}_{2} \mathrm{O}_{2}$ levels in the vicinity of the biofilms determined by SECM were much higher (mM range) compared to fluorescence-based $\mathrm{H}_{2} \mathrm{O}_{2}$ determination in the supernatant solution assay. Abucayon et al. [94] investigated the catalase activity of Vibrio fischeri biofilms. Catalase is able to produce oxygen as a by-product of the oxidation of $\mathrm{H}_{2} \mathrm{O}_{2}$ in a process called disproportionation, as a defence mechanism of the cells against oxidative stress. SECM measurements revealed that the level of $\mathrm{H}_{2} \mathrm{O}_{2}$ is related with the catalase activity, which changes with the time of incubation of the biofilm, in comparison with the planktonic bacteria. Theoretical modelling along the experiments predicted that the disproportionation of $\mathrm{H}_{2} \mathrm{O}_{2}$ to form $\mathrm{H}_{2} \mathrm{O}$ and $\mathrm{O}_{2}$ was $3 \times 10^{6}$ molecule of $\mathrm{H}_{2} \mathrm{O}_{2}$ per bacterium and second. The high activity of catalase e.g. allows bacteria to survive under the oxidative stress produced by the host against the colonization. To improve the detection limit of $\mathrm{H}_{2} \mathrm{O}_{2}$ in biological measurements, a platinum UME was modified with a multiwalled carbon nanotubePt nanoparticle-ionic liquid-based composite (Pt-MWCNTIL), which achieved a linear range from $250 \mathrm{nM}$ to $7 \mathrm{mM}$ and a sensitivity three times higher than that of other metalbased SECM probes [95]. The authors investigated the metabolic activity in the presence of glucose of $S$. gordonii biofilms by using a dual-Pt/Pt-MWCNT-IL sensor and the effect on the $\mathrm{H}_{2} \mathrm{O}_{2}$ profile in simulated human saliva conditions, i.e. adding lactoperoxidase (LPO) and potassium thiocyanate $\left(\mathrm{SCN}^{-}\right)$as $\mathrm{H}_{2} \mathrm{O}_{2}$-decomposing agents. Preliminary measurements showed that the presence of LPO and thiocyanate $\left(\mathrm{SCN}^{-}\right)$decreases the concentration of the $\mathrm{H}_{2} \mathrm{O}_{2}$. Thus, it could be assumed that the effects of oxidative stress on the oral cavity can be alleviated by the presence of LPO and $\mathrm{SCN}^{-}$.

SECM enables to determine in situ the local concentration of redox species with temporal and spatial resolution, which is highly attractive to quantitatively determine label-free redoxactive QS molecules. It is known that the activation of QS is concentration-dependent of the signalling molecules secreted by the bacteria and depends on the microbial population density [27]. In a collaborative effort, Connell et al. [92] and Koley et al. [93] used SECM to study quorum sensing at a bronchial human pathogenic bacterium Pseudomonas aeruginosa. Pyocyanin (PYO), a redox-active secondary metabolite (see Fig. 4a) secreted by $P$. aeruginosa, was studied in respect to the concentration profile of its reduced form above $P$. aeruginosa as high concentrations of this electroactive molecule are actively maintained by the bacteria. PYO is an important metabolite not only suppressing other microbes but also maintaining redox homeostasis and regulating biofilms in case of nutrient depletion [105]. The concentration gradient of reduced PYO, which is termed electrocline that extends up to several hundred microns into solution, was investigated in the presence of other electron acceptors like nitrate $\left(\mathrm{NO}_{3}{ }^{-}\right)$and in the presence of $\mathrm{Fe}^{3+}$ that actively re-oxidize PYO as shown in Fig. $4 \mathrm{~b}$. The authors also demonstrated the capability of SECM 


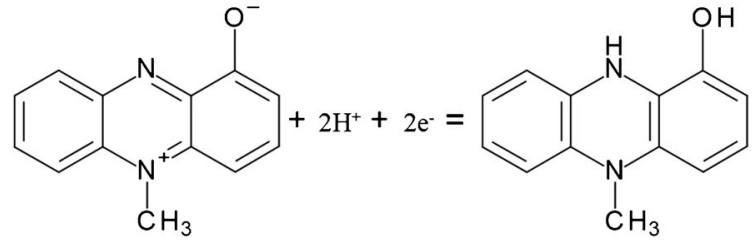
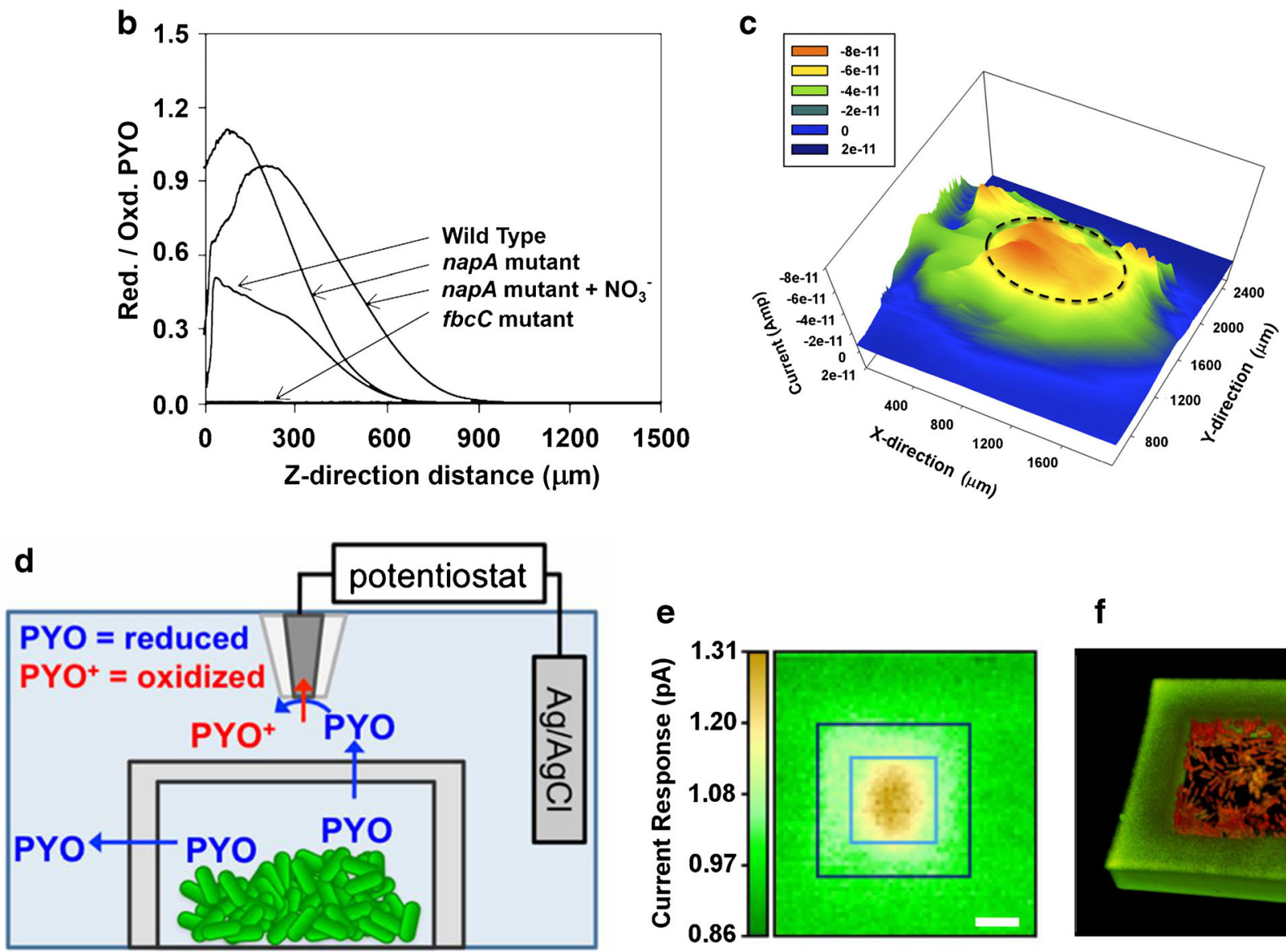

e

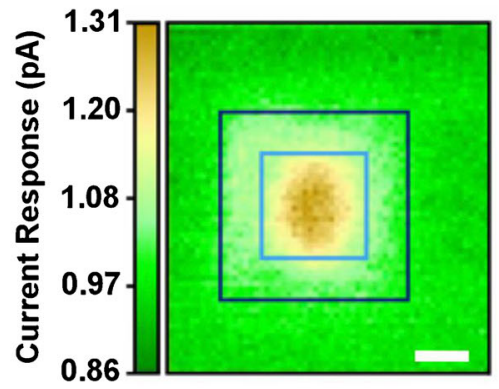

f

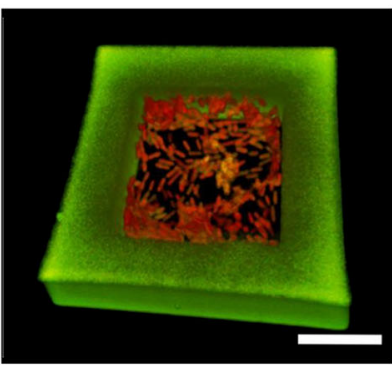

Fig. 4 (a) Redox reaction of pyocyanin. (b) The $z$-direction reduced pyocyanin (PYO) profiles above $P$. aeruginosa napA and fbcC mutants. (c) A constant height SECM image of a $P$. aeruginosa biofilm. $E_{\mathrm{tip}}=-$ 0.3 vs. $\mathrm{Ag} / \mathrm{AgCl}$ to oxidize PYO. Dotted line indicates the position of the biofilm. (a-c) Reproduced from Koley et al. [93], with permission from the National Academy of Sciences (copyright 2011). (d) Schematic of the microtrap-SECM system for measuring PYO in real time. (e) SECM

to image the concentration of PYO above $P$. aeruginosa as shown in Fig. 4c. In another SECM study [92], the authors investigated the distance of bacterial colonies trapped in $3 \mathrm{D}$ printed cages as shown in Fig. 4d. Two mutant strains of $P$. aeruginosa (PYO-producing strain and QS-responsive strain) were placed in microtraps separated by an $8-\mu \mathrm{m}$-thick wall. Aggregates with approx. 500 cells were sufficient to induce QS-mediated communication between the two cages. Figure $4 \mathrm{e}$ and $\mathrm{f}$ show a SECM image reflecting the concentration of PYO above a trap containing wild-type $P$. aeruginosa and the $3 \mathrm{D}$ confocal re-construction for counting the cells, respectively.

image of PYO response collected above a microtrap containing more than $500 \mathrm{WT} P$. aeruginosa. SECM tip potential of $0 \mathrm{~V}$ vs. $\mathrm{Ag} / \mathrm{AgCl}$ to oxidize the pyocyanin. (f) Three-dimensional confocal reconstruction that shows $\sim 700$ cells (red) in the microtrap (walls appear green). (a-c) Reproduced from Connell et al. [92], with permission from the National Academy of Sciences (copyright 2014)

A linear range limit of detection for PYO in SG/TC mode was reported with $2-120 \mu \mathrm{M}$, although no limit of quantification (LOQ) was given. Hence, it might be useful in future studies to consider whether the cell number-pyocyanin ratio is really due to the minimum concentration that has been produced by the bacteria or is defined by the limit of quantification of the electrochemical method.

Joshi et al. [88] and Ummadi et al. [106] recently presented potentiometric microsensors that could be also used for amperometric measurements (e.g. for positioning the microsensor in SECM experiments) by mixing ionophores with conductive carbon materials. For example, the group 
used a $\mathrm{Ca}^{2+}$ ion-selective microelectrode in combination with a dual microelectrode consisting of a bare Pt and a Pt-polyaniline $\mathrm{pH}$ microsensor in combination with SECM, mostly in stationary experiments, to monitor the $\mathrm{pH}$ and $\mathrm{Ca}^{2+}$ ion concentration profiles during the calcification process of Sporosarcina pasteurii biofilms. S. pasteurii is known to form calcite in the presence of urea and $\mathrm{Ca}^{2+}$ ions [107], hydrolyzing urea in brine solution, which results in an increase in local $\mathrm{pH}$ that causes the precipitation of calcite. The same group mapped with the carbon-based $\mathrm{pH}$ microsensor topography and $\mathrm{pH}$ profiles of pathogenic Streptococcus mutans biofilms, which belong to acidproducing bacteria as shown in Fig. 5a-c [88]. The authors also studied the metabolic interplay between the $\mathrm{H}_{2} \mathrm{O}_{2}$-producing S. gordonii and S. mutans organized in an alginate gel (Fig. 5d) in artificial saliva. In dependence of the buffer capacity of the artificial saliva, a gradual decrease in $\mathrm{H}_{2} \mathrm{O}_{2}$ concentration was observed over time accompanied by an acidification (decrease in $\mathrm{pH}$ value) as shown in Fig. 5e and f. Recently, the same group studied glucose uptake by
S. mutans with a microbiosensor based on glucose oxidase immobilized on functionalized multiwalled carbon nanotubes (f-MWCNTs) and 1-butyl-4-methyl-pyridinium hexafluorophosphate mixtures [108].

An example of SECM studies of anaerobic bacteria has been shown by Rudolph et al. [109]. The activity of $\mathrm{Fe}(\mathrm{III})$ and $\mathrm{Mn}(\mathrm{IV})-$ reducing proteins isolated from the outer membrane of Shewanella oneidensis was investigated. The extracted metal reductase complexes were separated by gel electrophoresis prior to SECM studies (schematically shown in Fig. 6a), which were performed in combination with square-wave anodic stripping voltammetry (SWASV) at $\mathrm{Hg} / \mathrm{Pt}$ microelectrodes. Changes in concentration of iron(III) and the evolvement of a peak associated to sulphur species were monitored over time (Fig. 6b). Moreover, square-wave voltammograms above active and inactive reductase proteins confirmed the evidence of the enzymatic process, since iron(II) signal above the inactive enzyme was absent, as shown in Fig. 6c.
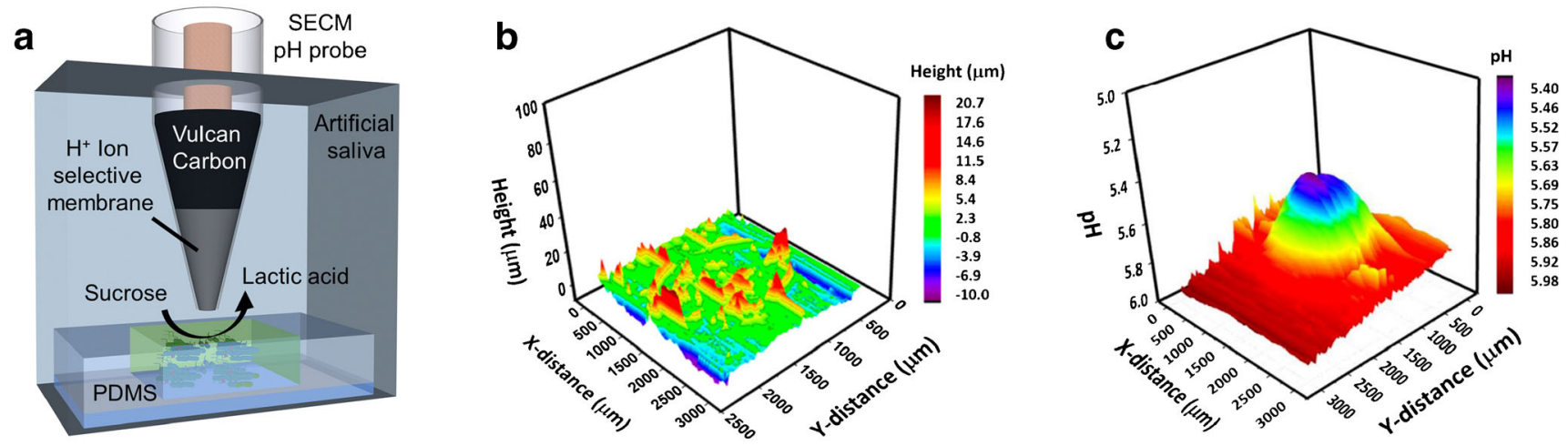

d

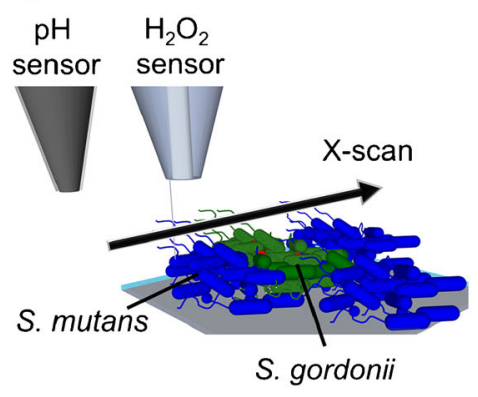

e

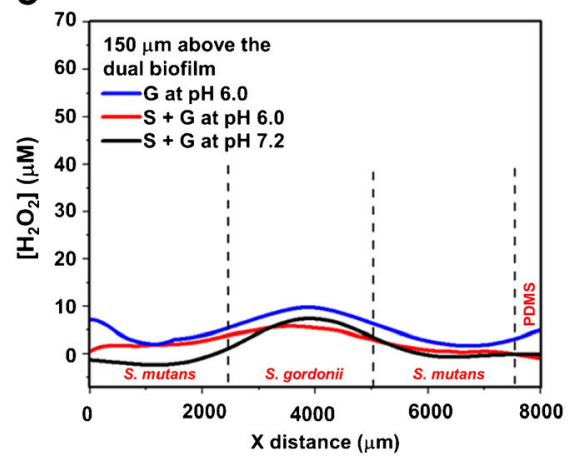

$f$

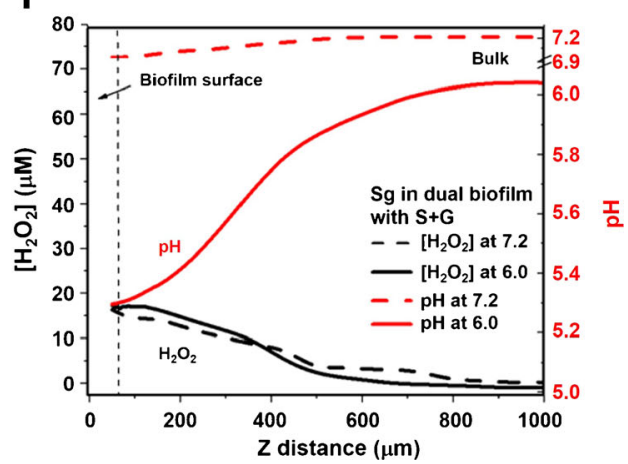

Fig. 5 (a) Schematic of the $S$. mutans bacterial gel biofilm substrate and the $\mathrm{pH}$ microprobe used in SECM experiments. (b) Three-dimensional morphological image of the $S$. mutans bacterial gel biofilm substrate recorded $60 \mu \mathrm{m}$ above the biofilm with the $\mathrm{pH}$ microprobe (scan speed, $30 \mu \mathrm{m} / \mathrm{s}$ ) in $1 \mathrm{mM}$ ferrocenemethanol in artificial saliva $(\mathrm{pH} 7.2)$ at $23{ }^{\circ} \mathrm{C}$. (c) Three-dimensional $\mathrm{pH}$ image recorded $60 \mu \mathrm{m}$ above the biofilm with the $\mathrm{pH}$ microprobe (scan speed, $30 \mu \mathrm{m} / \mathrm{s}$ ) after the addition of $30 \mathrm{mM}$ sucrose in artificial saliva ( $\mathrm{pH} \mathrm{6.0)}$ at $37^{\circ} \mathrm{C}$. (d) Scheme of dual recording using a $\mathrm{pH}$ microsensor and a $\mathrm{H}_{2} \mathrm{O}_{2}$ microsensor. (e) $x$-direction $\mathrm{H}_{2} \mathrm{O}_{2}$ profile $150 \mu \mathrm{m}$ above the dual bacterial biofilm in the presence of glucose (G) and glucose + sucrose (S) at $\mathrm{pH} 6.0$ and 7.2. (d) $z$-direction $\mathrm{H}_{2} \mathrm{O}_{2}$ and $\mathrm{pH}$ profile from $50 \mu \mathrm{m}$ above $S$. gordonii in the dual bacterial biofilm to $1000 \mu \mathrm{m}$ above in the bulk solution in the presence of $\mathrm{G}+\mathrm{S}$ at $\mathrm{pH} 6.0$ (solid lines) and 7.2 (dashed lines). (b), (c), (e), (f) Reprinted from Joshi et al. [88], with permission from the American Chemical Society (copyright 2017) 
a

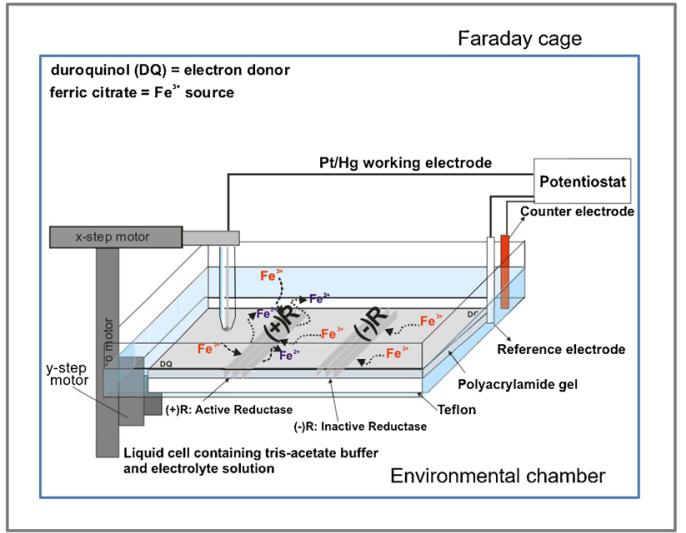

b

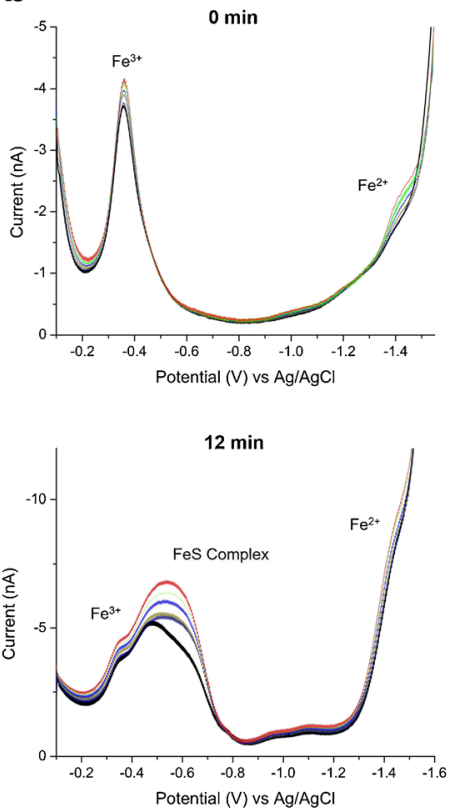

C

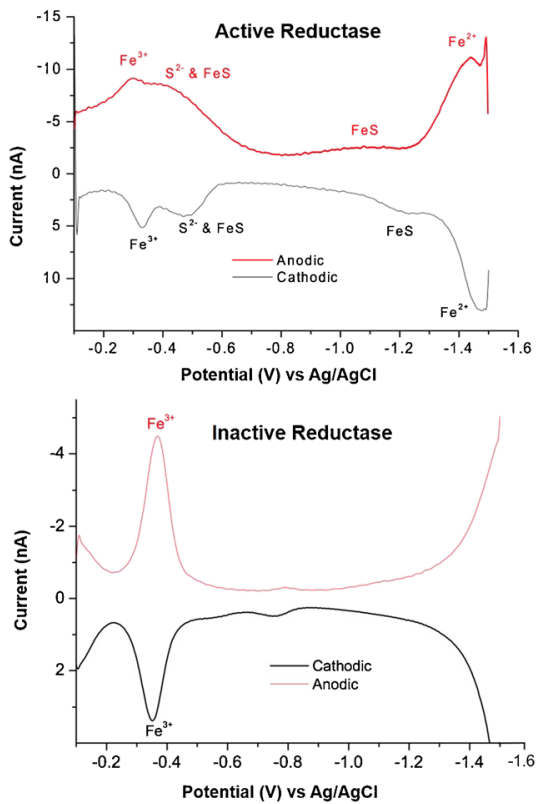

Fig. 6 (a) Scheme of the SECM experimental setup within the environmental chamber controlling the $\mathrm{O}_{2}$ content below $2.5 \mathrm{ppm}$. (b) Square-wave voltammograms recorded at a $\mathrm{Pt} / \mathrm{Hg}$ microelectrode positioned at $36 \mu \mathrm{m}$ above the active reductase complexes (top) start of

\section{Antibacterial agents}

Forming biofilms provides protection to bacteria and ensures tolerance against antimicrobial treatments in comparison to their planktonic form. In recent years, strong efforts have been dedicated to the development of antimicrobial measures as biofilms are quite difficult to eradicate. In clinical scenarios, multiresistant bacterial strains present a significant threat as $75 \%$ of infections are related to biofilm formation. Quorum quenching enzymes [110], adhesin repressors [111], nanoparticle-based copolymers $[56,112]$ and metal-chelator approaches $[113,114]$ have been studied so far to prevent biofilm formation or to eradicate biofilms. To date, only a few studies concerning antimicrobial effects have been published using SECM [82, 112, 115, 116]. Silver nanoparticles (AgNPs) and $\mathrm{Ag}(\mathrm{I})$ at low concentrations are known as a very powerful antimicrobial agent, which, to date, are used in many consumer products and clinical applications [117]. Studies on the antibacterial mechanisms of Ag ions and AgNPs (smaller $<10 \mathrm{~nm}$ ) showed that e.g. Ag ions react with peptidoglycans, resulting in cell membrane damage. Ag ions can also penetrate the cells, inducing increased levels of ROS and disruption of DNA replication cycles. The full mechanism of $\mathrm{Ag}(\mathrm{I})$-induced cell death is not yet fully understood [118]. Holt and Bard [82] studied the influence of $\mathrm{Ag}$ ion concentration in respect to its toxicity using microelectrochemical and SECM experiments to measure oxygen and $\mathrm{Ag}(\mathrm{I})$ uptake by $E$. coli under different experimental conditions. Using a Clark microelectrode, the change of oxygen concentration over E. coli cells was measurements at $0 \mathrm{~min}$ and (bottom) after $12 \mathrm{~min}$. (c) Square-wave voltammograms recorded (top) above the redox-active protein and (bottom) above the inactive protein. Reprinted from Rudolph et al. [109], with permission from Elsevier

monitored over time at different concentrations of $\mathrm{AgNO}_{3}$ in the presence of glucose. With these experiments, the authors showed that at a concentration of $\operatorname{Ag}(\mathrm{I}) \leq 10 \mathrm{mM}$, a stimulation of the bacterial respiration is triggered before cell death starts. Comparing this data with experiments performed with ferricyanide as an electron acceptor, the authors concluded that $\mathrm{Ag}(\mathrm{I})$ may block the electron flow in the electron transport chain breaking the respiratory chain.

NPs, e.g. AgNPs embedded in polymeric matrices, allow a controlled release, which the degree of release can be tuned by the loading of NPs into the polymeric films [119]. The kinetics and temporal release behaviour of AgNPs and Ag ions can be studied locally via SECM, which provides in situ information on the oxidation state of the AgNPs embedded in the polymeric film [112]. Release studies of $\mathrm{Ag}(\mathrm{I})$ were performed via SECM in combination with anodic stripping voltammetry (ASV) [120], which enabled to detect selectively low concentrations of $\mathrm{Ag}(\mathrm{I})$. Oxidized $\mathrm{Ag}$ ions are first reduced $\left(\mathrm{Ag}^{0}\right)$ at the surface of the Pt UME and then again stripped of (oxidized) as shown in Fig. 7a. Accumulation over time is shown in Fig. 7b, where oxidation current is proportional to the concentration of $\operatorname{Ag}(\mathrm{I})$. Alternatively, the reaction shown in Eq. (1) can be used to determine the Ag concentration

$\left[\mathrm{Ir}(\mathrm{Cl})_{6}\right]^{2-}+\mathrm{Ag}^{0} \rightarrow\left[\operatorname{Ir}(\mathrm{Cl})_{6}\right]^{3-}+\mathrm{Ag}^{+}$

Feedback mode SECM experiments, as shown in Fig. 7c and $\mathrm{d}$ can be used to determine the electrochemical nature of 

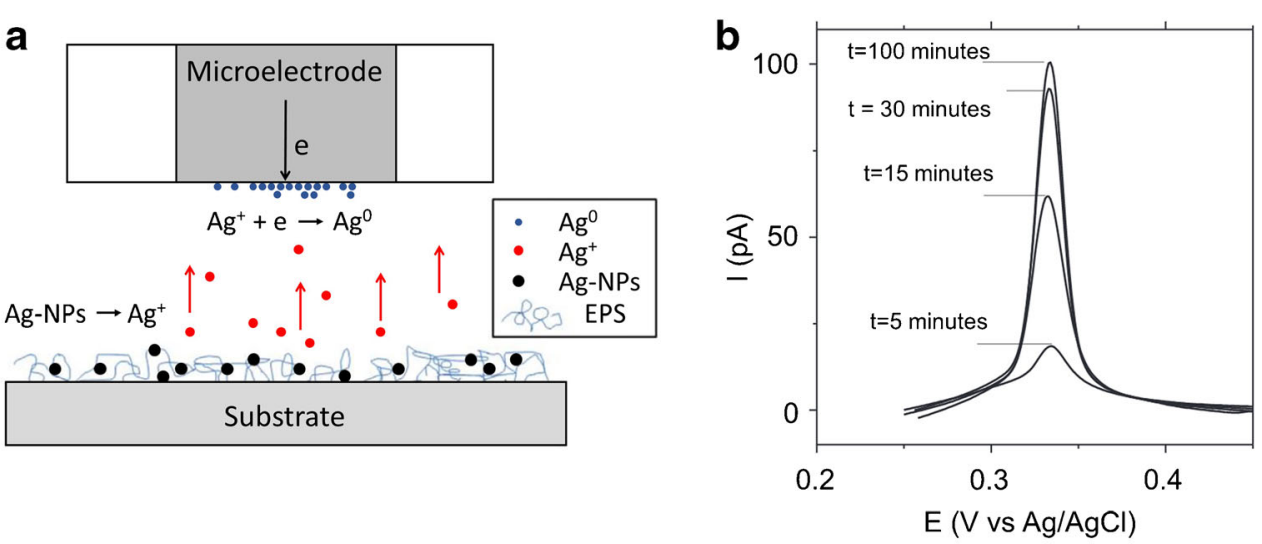
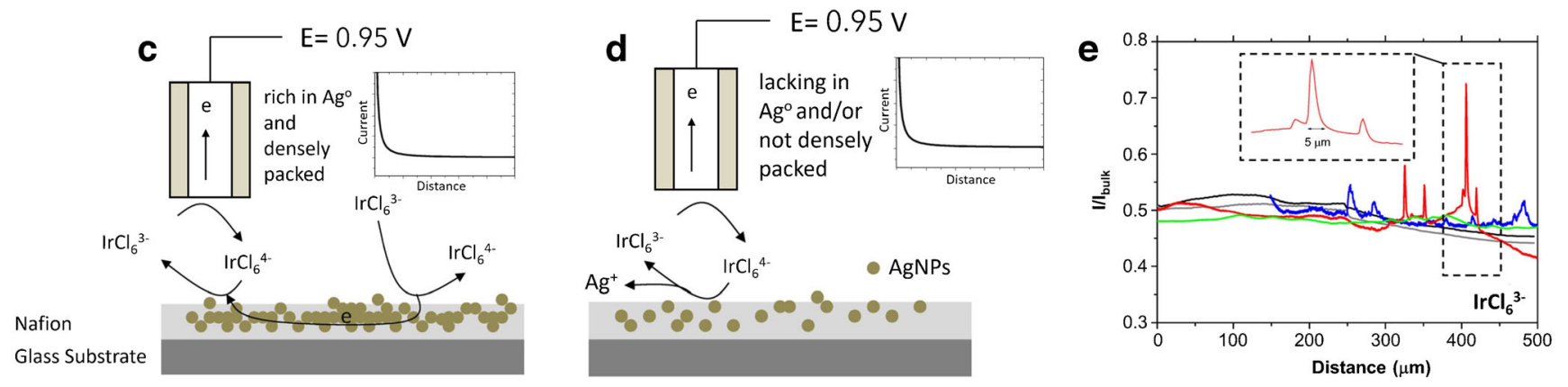

Fig. 7 (a) Schematic of $\operatorname{Ag}(\mathrm{I})$ collection at the SECM tip. (b) Representative ASVs recorded above an AgNP-exopolysaccharide (EPS) surface over time. Reprinted from Battistel et al. [120], with permission from Elsevier. (c) Schematic of feedback mode experiments using $\left[\operatorname{Ir}(\mathrm{Cl})_{6}\right]^{3-}$ as a redox mediator to study AgNP-rich surface. (d)

the AgNPs using $\left[\operatorname{Ir}(\mathrm{Cl})_{6}\right]^{3-}$ as a redox mediator. The regeneration of the redox mediator occurs only in the presence of $\mathrm{Ag}^{0}$ (positive feedback); however, in the absence or low density of AgNPs, the redox species is not re-generated, and a negative feedback is recorded. Pecchielan et al. [112] demonstrated such Ag release studies at Nafion films loaded with AgNPs (as shown in Fig. 7e).

Although to date only a limited number of papers have been published on the utility of SECM in bacterial research, within recent years, interest sparked due to the versatility of the technique and the improvements in hardware and imaging modes for studying life cells [121]. Table 1 presents an overview on studies conducted in the last decade using SECM and combined SECM techniques to investigate biofilms and antimicrobial agents.

\section{Future potential of hybrid SECM techniques}

In recent years, significant efforts have been dedicated to not only instrumental developments, for example incubator cells, which allow controlling the environment of the biological samples, but also hybrid SECM techniques, such as combining SECM with fluorescence microscopy for life sciences [124, 125] or hybrid scanning probe microscopy (SPM) methods taking advantage of SECM such as combined SICM-SECM
Schematic of feedback mode experiments using $\left[\operatorname{Ir}(\mathrm{Cl})_{6}\right]^{3-}$ as a redox recorded above the AgNP-Nafion surfaces using $\left[\operatorname{Ir}(\mathrm{Cl})_{6}\right]^{3-}$ as a redox mediator. Reprinted from Pecchielan et al. [112], with permission from John Wiley and Sons

[126] or AFM-SECM [127, 128]. Although such hybrid techniques have not yet been fully explored for studying bacteria, biofilms or antimicrobial coatings, in the future, they might have significant potential for improved lateral resolution along with correlating topographical changes to metabolic activity of biofilms. Also, combining adhesion measurements with mapping molecules appears highly attractive for in-depth understanding of the first steps of bacterial adhesion.

Fluorescence microscopy has been intensively used to study biofilms and can be easily combined with SECM for life science studies. Cannan et al. [129], for example, used a microelectrode to change locally the $\mathrm{pH}$ via reduction of benzoquinone (BQ) to hydroquinone (HQ), a reaction that alkalizes the medium. As BQ is a fluorescent molecule and its concentration is $\mathrm{pH}$-dependent, the $3 \mathrm{D}$ images obtained by CLSM correspond to the $\mathrm{pH}$ gradient adjacent to the electrode surface and are a function of the applied electrode potential. The combination of fluorescence with SECM has allowed researchers to study simultaneously the behaviour of small electroactive and fluorescent molecules which play a significant role in cellular processes such as ROS. Salamifar and Lai [125] monitored intracellular and extracellular ROS levels of prostate cancer cells using hybrid SECM-fluorescence microscopy, as shown schematically in Fig. 8a. An approach that is highly interesting to study biofilms as $\mathrm{H}_{2} \mathrm{O}_{2}$ or $\mathrm{pH}$ could be mediator at a surface with low density of AgNPs. (e) SECM $x$-line scans 
Table 1 Applications of SECM for biofilm studies of bacterial and microbial cultures showing the examined species, the detected analyte and the used SECM probe

\begin{tabular}{|c|c|c|c|}
\hline UME & Family of bacteria & Species detected & Reference \\
\hline Platinum & Pseudomonas aeruginosa & PYO & {$[92,93]$} \\
\hline Pt-MWCNT-IL-GOD ${ }^{\mathrm{a}}$ & Streptococcus mutans & Glucose & {$[108]$} \\
\hline Platinum & Escherichia coli & p-Aminophenol & [98] \\
\hline Platinum & Escherichia coli & {$\left[\mathrm{Fe}(\mathrm{CN})_{6}\right]^{3-/ 4-}$} & {$[82,97]$} \\
\hline Platinum & Vibrio fischeri & $\mathrm{H}_{2} \mathrm{O}_{2}$ & [94] \\
\hline Gold & S. gordonii and A. actinomycetemcomitans & $\mathrm{H}_{2} \mathrm{O}_{2}$ & [81] \\
\hline Pt-MWCNT-IL ${ }^{b}$ & S. gordonii & $\mathrm{H}_{2} \mathrm{O}_{2}$ & {$[95]$} \\
\hline Clark UME & Escherichia coli & $\mathrm{O}_{2}$ & {$[82]$} \\
\hline $\mathrm{Ca}^{2+}$ microsensor & Sporosarcina pasteurii & $\mathrm{Ca}^{2+}$ & [107] \\
\hline Platinum & Escherichia coli & $\mathrm{Cu}^{2+}$ & {$[122]$} \\
\hline $\mathrm{Pt} / \mathrm{Hg} \mathrm{UME}$ & Shewanella oneidensis & $\mathrm{Mn}^{2+}, \mathrm{Fe}^{2+}, \mathrm{S}^{2-}$ & [109] \\
\hline Platinum-polyaniline & Sporosarcina pasteurii & $\mathrm{pH}$ & {$[107]$} \\
\hline $\mathrm{pH}$ sensor & S. gordonii and $S$. mutans & $\mathrm{pH}$ & {$[88]$} \\
\hline Platinum disk-silver ring & Escherichia coli & $\mathrm{Ag}^{+}$ & {$[82]$} \\
\hline Platinum & Antimicrobial surface & $\mathrm{Ag}^{+}$ & {$[112]$} \\
\hline Platinum & Shewanella oneidensis & $\mathrm{H}^{+}$ & {$[123]$} \\
\hline
\end{tabular}

$U M E$ ultramicroelectrode

${ }^{\text {a }}$ Multiwalled carbon nanotubes in ionic liquid electrode functionalized with glucose oxidase

${ }^{\mathrm{b}}$ Multiwalled carbon nanotubes in ionic liquid electrode

SECM-IR-ATR

SECM-Fluorescence

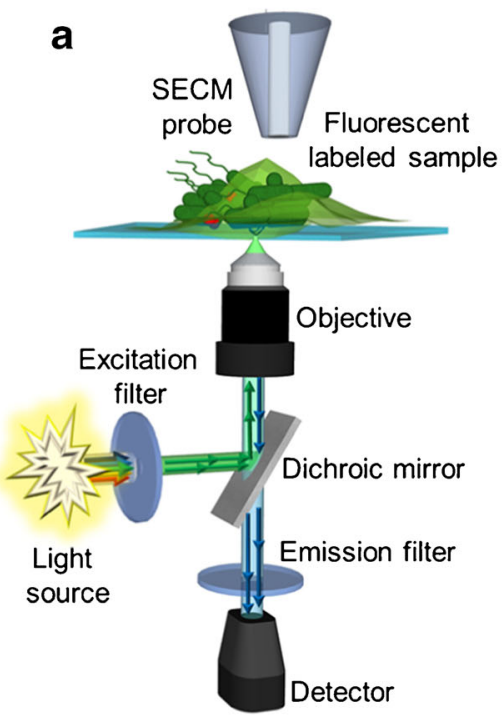

\section{b}

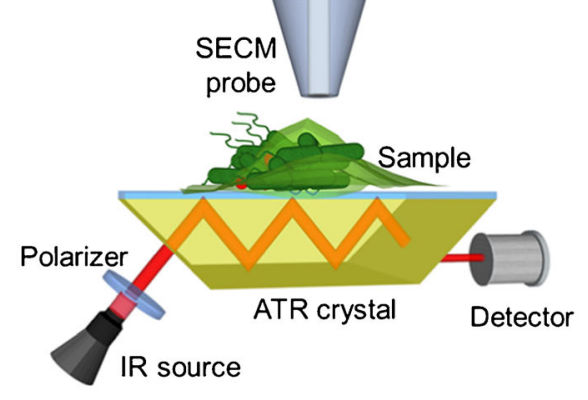

d

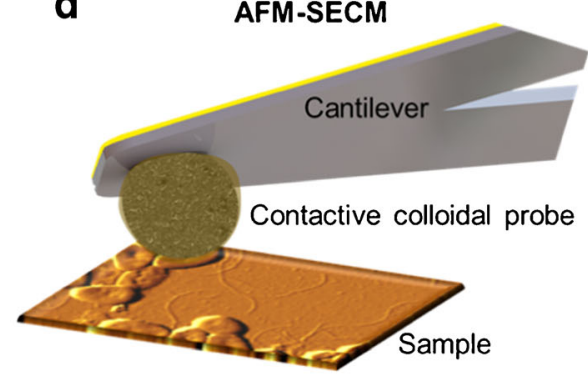

SECM-SICM

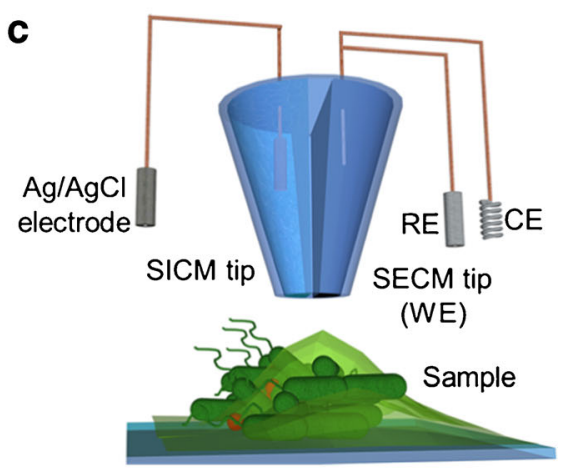

e

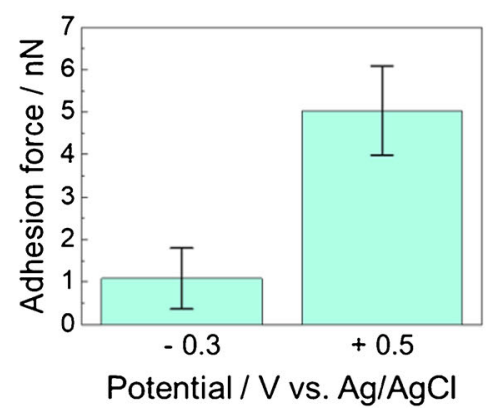

Fig. 8 Schemes of SECM hybrid techniques. (a) SECM combined with fluorescence microscopy. (b) SECM in combination with IR-ATR. (c) SICMSECM. (d) Colloidal AFM-SECM. (e) Adhesion measurements at the single bacterial level recorded with a biased colloidal AFM-SECM probe 
studied within and in close proximity at the biofilm. Electrochemical fluorophores, such as resazurin and tetrazines, used as respiration indicators to study bacteria and biofilm behaviour [130], have been tested as redox mediators. Guerret-Legras et al. [131, 132] showed that the fluorescence intensity of these molecules is a function of the potential of the SECM probe, independent of the substrate potential with the tip-substrate distance controlling the fluorescence amplitude. Hence, electrochemically induced processes in biological and microbial samples could be investigated with high spatial resolution.

Among the hybrid SPM techniques, the combination of SECM and SICM (Fig. 8c) will have advantages for studying biofilms, as this hybrid technique is truly non-invasive and significantly improves not only the achievable resolution as nanoelectrodes can be fabricated through carbon deposition methods inside the nanopipette, but it also allows to control the tip-substrate distance. This hybrid technique has been applied to investigate the local cell membrane permeability of electroactive species in myocyte cells [133] and cellular uptake at Zea mays root hair cells [134], but it has not yet been used for studying biofilms. However, the demonstrated highly localized uptake could contribute to understanding the efficacy in drug uptake or antimicrobial agents. The possibility to combine SECM with AFM has been demonstrated during the last two decades. AFM-SECM (Fig. 8d) allows, next to electrochemical imaging, simultaneously recording physical and highresolution morphological information of the sample. AFMSECM has been used to study biologically/biomedically relevant problems, i.e. mapping the flux of biomedically relevant electroactive molecules [128], detection of single-protein molecules at isolated viruses [127, 135] and mapping adhesion properties of mouse fibroblasts using conductive polymermodified colloidal AFM-SECM probes [136]. Recently, Daboss et al. [137] investigated the adhesion of Pseudomonas fluorescens at the single bacterial cell level using polydopamine (PDA)-modified colloidal AFM-SECM probes. The functional groups of PDA can be selectively switched via the applied potential of the AFM-SECM probe, changing the adhesion forces due to the change in surface charges (as shown Fig. 8e). Combining SPM techniques with spectroscopic methods, for example combining SECM with IR-ATR (Fig. 8b) or Raman spectroscopy, is highly attractive to provide, next to electrochemical information, e.g. mapping respiratory activity and $\mathrm{pH}$, also molecular-specific information on changes of the biofilm matrix. In general, hybrid methods have significant advantages as complementary information may be obtained simultaneously, eliminating uncertainties when interpreting separately albeit consecutively recorded information on complex samples such as biofilms. For example, combining SECM with confocal fluorescence microscopy would allow to map the changes in $\mathrm{pH}$ inside as well as $\mathrm{pH}$ changes in the local bacterial microenvironment at the same sample.

\section{Conclusions and future perspectives}

This review highlights applications and potential of SECM for understanding key aspects in biofilm formation, monitoring metabolites and to elucidate quorum sensing/quenching processes, as well as to investigate antimicrobial effects. Many studies on the chemical composition and occurrence/disappearance of molecules are still performed ex situ, yet SECM may have significant advantages as information is obtained in situ and with temporal and spatial resolution.

An application area, which was not discussed in this review, is microbiologically induced corrosion (MIC), which is estimated to be a major cause for corrosion damage of metals, and is currently, predominantly studied using conventional electrochemical techniques. The ability of bacteria to use metals as electron donor in their respiration processes promotes the anodic dissolution of the metals with a corrosion rate, which is much higher than that in the absence of bacteria. As biofilms cause localized corrosion, SECM is a very suitable method to study processes including pit formation [138]. Hence, SECM may contribute to elucidate the role of bacteria and processes involved in biocorrosion and improve anticorrosive and antibiofilm treatments.

In particular, hybrid methods may allow in the future to contribute significantly to studies in heterogenous microbial systems. Considering the recently made instrumental improvements/developments in hyphenated methods, in particular in SPM, one can state: "there is plenty of room at the bottom," which may, in the future, benefit microbial research. However, due to the complexity of biofilms, there is also a need for well-designed control experiments and a sufficient number of experiments to obtain meaningful statistical data, which might be sometimes challenging with these advanced high-resolution SPM methods.

Another interesting aspect to enhance SECM studies on complex samples such as biofilms in the future may be related to integrated machine learning approaches to perform automated SECM experiments. Barforoush et al. [139] implemented fuzzy logic algorithm for an automated approach of the SECM tip at different substrates (conductive and insulating) in addition to an automated tip/substrate alignment protocol. Screening approaches for photocatalyst and electrocatalyst have been demonstrated via SECM, although automated workflows and advanced robotics as demonstrated in i.e. materials science [140] have not yet been demonstrated for SECM.

Acknowledgements This work is part of the "Break Biofilm" project that has received funding from the European Union's 2020 research and innovation program under the Marie Skłodowska Curie Grant Agreement No. 813439. 
Funding Information Open Access funding provided by Projekt DEAL.

\section{Compliance with ethical standards}

Conflict of interest The authors declare that they have no conflict of interest.

Open Access This article is licensed under a Creative Commons Attribution 4.0 International License, which permits use, sharing, adaptation, distribution and reproduction in any medium or format, as long as you give appropriate credit to the original author(s) and the source, provide a link to the Creative Commons licence, and indicate if changes were made. The images or other third party material in this article are included in the article's Creative Commons licence, unless indicated otherwise in a credit line to the material. If material is not included in the article's Creative Commons licence and your intended use is not permitted by statutory regulation or exceeds the permitted use, you will need to obtain permission directly from the copyright holder. To view a copy of this licence, visit http://creativecommons.org/licenses/by/4.0/.

\section{References}

1. Høiby N. A short history of microbial biofilms and biofilm infections. APMIS. 2017;125:272-5. https://doi.org/10.1111/apm. 12686.

2. Costerton JW, Cheng KJ, Geesey GG, Ladd TI, Nickel JC, Dasgupta $\mathrm{M}$, et al. Bacterial biofilms in nature and disease. Annu Rev Microbiol. 1987;41:435-64. https://doi.org/10.1146/ annurev.mi.41.100187.002251.

3. Mah TFC, O'Toole GA. Mechanisms of biofilm resistance to antimicrobial agents. Trends Microbiol. 2001;9:34-9. https://doi. org/10.1016/S0966-842X(00)01913-2.

4. O'May GA, Jacobsen SM, Stickler DJ, HLT M, Shirtliff ME. Complicated urinary tract infections due to catheters. Role Biofilms Device-Related. 2008;21:123-65. https://doi.org/10. 1007/7142.

5. Chen $\mathrm{M}, \mathrm{Yu} \mathrm{Q}$, Sun $\mathrm{H}$. Novel strategies for the prevention and treatment of biofilm related infections. Int J Mol Sci. 2013;14: 18488-501. https://doi.org/10.3390/ijms140918488.

6. Arciola CR, Campoccia D, Montanaro L. Implant infections: adhesion, biofilm formation and immune evasion. Nat Rev Microbiol. 2018;16:397-409. https://doi.org/10.1038/s41579018-0019-y.

7. Zhao X, Zhao F, Wang J, Zhong N. Biofilm formation and control strategies of foodborne pathogens: food safety perspectives. RSC Adv. 2017;7:36670-83. https://doi.org/10.1039/C7RA02497E.

8. Danhorn T, Fuqua C. Biofilm formation by plant-associated bacteria. Annu Rev Microbiol. 2007;61:401-22. https://doi.org/10. 1146/annurev.micro.61.080706.093316.

9. Ma Y, Zhang Y, Zhang R, Guan F, Hou B, Duan J. Microbiologically influenced corrosion of marine steels within the interaction between steel and biofilms: a brief view. Appl Microbiol Biotechnol. 2020;104:515-25. https://doi.org/10. 1007/s00253-019-10184-8.

10. Li W, Zheng T, Ma Y, Liu J. Current status and future prospects of sewer biofilms: their structure, influencing factors, and substance transformations. Sci Total Environ. 2019;695:133815. https://doi. org/10.1016/j.scitotenv.2019.133815.

11. Loto CA. Microbiological corrosion: mechanism, control and impact — a review. Int J Adv Manuf Technol. 2017;92:4241-52. https://doi.org/10.1007/s00170-017-0494-8.
12. Bjarnsholt T, Buhlin K, Dufrêne YF, Gomelsky M, Moroni A, Ramstedt M, et al. Biofilm formation - what we can learn from recent developments. J Intern Med. 2018;284:332-45. https://doi. org/10.1111/joim.12782.

13. Flora M, Perrotta F, Nicolai A, Maffucci R, Pratillo A, Mollica M, et al. Staphylococcus aureus in chronic airway diseases: an overview. Respir Med. 2019;155:66-71. https://doi.org/10.1016/j. rmed.2019.07.008.

14. Humphrey T. Salmonella, stress responses and food safety. Nat Rev Microbiol. 2004;2:504-9. https://doi.org/10.1038/ nrmicro907.

15. Dogan B, Boor KJ. Genetic diversity and spoilage potentials among Pseudomonas spp. isolated from fluid milk products and dairy processing plants. Appl Environ Microbiol. 2003;69:130-8. https://doi.org/10.1128/AEM.69.1.130-138.2003.

16. Faille C, Bénézech T, Midelet-Bourdin G, Lequette Y, Clarisse M, Ronse G, et al. Sporulation of Bacillus spp. within biofilms: a potential source of contamination in food processing environments. Food Microbiol. 2014;40:64-74. https://doi.org/10.1016/ j.fm.2013.12.004.

17. Kocot AM, Olszewska MA. Biofilm formation and microscopic analysis of biofilms formed by Listeria monocytogenes in a food processing context. LWT. 2017;84:47-57. https://doi.org/10. 1016/j.lwt.2017.05.042.

18. Kanematsu H, Barry DM. Formation and control of biofilm in various environments. Singapore: Springer Singapore; 2020. https://doi.org/10.1007/978-981-15-2240-6.

19. Schneider K, van der Werf W, Cendoya M, Mourits M, NavasCortés JA, Vicent A, et al. Impact of Xylella fastidiosa subspecies pauca in European olives. Proc Natl Acad Sci U S A. 2020;117: 9250-9. https://doi.org/10.1073/pnas.1912206117.

20. Xu X, Liu W, Tian S, Wang W, Qi Q, Jiang P, et al. Petroleum hydrocarbon-degrading bacteria for the remediation of oil pollution under aerobic conditions: a perspective analysis. Front Microbiol. 2018;9:1-11. https://doi.org/10.3389/fmicb.2018. 02885 .

21. Kang C-H, Kwon Y-J, So J-S. Bioremediation of heavy metals by using bacterial mixtures. Ecol Eng. 2016;89:64-9. https://doi.org/ 10.1016/j.ecoleng.2016.01.023.

22. Verbeke F, De Craemer S, Debunne N, Janssens Y, Wynendaele $\mathrm{E}$, Van de Wiele C, et al. Peptides as quorum sensing molecules: measurement techniques and obtained levels in vitro and in vivo. Front Neurosci. 2017;11:1-18. https://doi.org/10.3389/fnins. 2017.00183.

23. Flemming HC, Wingender J, Szewzyk U, Steinberg P, Rice SA, Kjelleberg S. Biofilms: an emergent form of bacterial life. Nat Rev Microbiol. 2016;14:563-75. https://doi.org/10.1038/nrmicro. 2016.94.

24. Costerton JW, Stewart PS, Greenberg EP. Bacterial biofilms: a common cause of persistent infections. Science. 1999;284:1318 22. https://doi.org/10.1126/science.284.5418.1318.

25. Wimpenny J, Manz W, Szewzyk U. Heterogeneity in biofilms. FEMS Microbiol Rev. 2000;24:661-71. https://doi.org/10.1111/j. 1574-6976.2000.tb00565.x.

26. Wan N, Wang H, Ng CK, Mukherjee M, Ren D, Cao B, et al. Bacterial metabolism during biofilm growth investigated by $13 \mathrm{C}$ tracing. Front Microbiol. 2018;9:1-9. https://doi.org/10.3389/ fmicb.2018.02657.

27. Irie Y, Parsek MR. Quorum sensing and microbial biofilms. In: Romeo T, editor. Bacterial biofilms. 322nd ed. Berlin, Heidelberg: Springer Berlin Heidelberg; 2008. p. 67-84. https://doi.org/10. 1007/978-3-540-75418-3_4.

28. Girard L, Blanchet É, Intertaglia L, Baudart J, Stien D, Suzuki M, et al. Characterization of $\mathrm{N}$-acyl homoserine lactones in Vibrio tasmaniensis LGP32 by a biosensor-based UHPLC-HRMS/MS 
method. Sensors. 2017;17:906. https://doi.org/10.3390/ s17040906.

29. Smith RS, Harris SG, Phipps R, Iglewski B. The Pseudomonas aeruginosa quorum-sensing molecule N-(3oxododecanoyl)homoserine lactone contributes to virulence and induces inflammation in vivo. J Bacteriol. 2002;184:1132-9. https://doi.org/10.1128/jb.184.4.1132-1139.2002.

30. Henke JM, Bassler BL. Bacterial social engagements. Trends Cell Biol. 2004;14:648-56. https://doi.org/10.1016/j.tcb.2004.09.012.

31. Finlay BB, Falkow S. Common themes in microbial pathogenicity revisited. Microbiol Mol Biol Rev. 1997;61:136-69.

32. Pratt LA, Kolter R. Genetic analysis of Escherichia coli biofilm formation: roles of flagella, motility, chemotaxis and type I pili. Mol Microbiol. 1998;30:285-93. https://doi.org/10.1046/j.13652958.1998.01061.x.

33. Birarda G, Delneri A, Lagatolla C, Parisse P, Cescutti P, Vaccari $\mathrm{L}$, et al. Multi-technique microscopy investigation on bacterial biofilm matrices: a study on Klebsiella pneumoniae clinical strains. Anal Bioanal Chem. 2019;411:7315-25. https://doi.org/ 10.1007/s00216-019-02111-7.

34. Bridier A, Tischenko E, Dubois-Brissonnet F, Herry J-M, Thomas V, Daddi-Oubekka S, et al. Deciphering biofilm structure and reactivity by multiscale time-resolved fluorescence analysis. In: Linke D, Goldman A, editors. Bact. Adhes. Adv. Exp. Med. Biol., Springer, Dordrecht; 2011, p. 333-49. https://doi.org/10. 1007/978-94-007-0940-9 21.

35. Watrous JD, Dorrestein PC. Imaging mass spectrometry in microbiology. Nat Rev Microbiol. 2011;9:683-94. https://doi.org/10. 1038/nrmicro2634.

36. Renslow RS, Lindemann SR, Cole JK, Zhu Z, Anderton CR. Quantifying element incorporation in multispecies biofilms using nanoscale secondary ion mass spectrometry image analysis. Biointerphases. 2016;11:02A322. https://doi.org/10.1116/1. 4941764.

37. Resch A, Leicht S, Saric M, Pásztor L, Jakob A, Götz F, et al. Comparative proteome analysis of Staphylococcus aureus biofilm and planktonic cells and correlation with transcriptome profiling. Proteomics. 2006;6:1867-77. https://doi.org/10.1002/pmic. 200500531.

38. De Angelis M, Siragusa S, Campanella D, Di Cagno R, Gobbetti M. Comparative proteomic analysis of biofilm and planktonic cells of Lactobacillus plantarum DB200. Proteomics. 2015;15: 2244-57. https://doi.org/10.1002/pmic.201400363.

39. Donné J, Dewilde S. The challenging world of biofilm physiology. vol. 67. 1st ed. Elsevier Ltd.; 2015. https://doi.org/10.1016/bs. ampbs.2015.09.003.

40. Pousti M, Zarabadi MP, Abbaszadeh Amirdehi M, PaquetMercier F, Greener J. Microfluidic bioanalytical flow cells for biofilm studies: a review. Analyst. 2019;144:68-86. https://doi. org/10.1039/c8an01526k.

41. Sankaran J, Karampatzakis A, Rice SA, Wohland T. Quantitative imaging and spectroscopic technologies for microbiology. FEMS Microbiol Lett. 2018;365:1-12. https://doi.org/10.1093/femsle/ fny075.

42. El-Kirat-Chatel S, Beaussart A, Mathelié-Guinlet M, Dufrêne YF. The importance of force in microbial cell adhesion. Curr Opin Colloid Interface Sci. 2020;47:111-7. https://doi.org/10.1016/j. cocis.2019.12.010

43. Lorite GS, Janissen R, Clerici JH, Rodrigues CM, Tomaz JP, Mizaikoff B, et al. Surface physicochemical properties at the micro and nano length scales: role on bacterial adhesion and Xylella fastidiosa biofilm development. PLoS One. 2013;8:e75247. https://doi.org/10.1371/journal.pone.0075247.

44. Helenius J, Heisenberg C-P, Gaub HE, Muller DJ. Single-cell force spectroscopy. J Cell Sci. 2008;121:1785-91. https://doi. org/10.1242/jcs.030999.
45. Burgain J, Scher J, Lebeer S, Vanderleyden J, Corgneau M, Guerin J, et al. Impacts of $\mathrm{pH}$-mediated EPS structure on probiotic bacterial pili-whey proteins interactions. Colloids Surf B: Biointerfaces. 2015;134:332-8. https://doi.org/10.1016/j. colsurfb.2015.06.068.

46. Zeng G, Müller T, Meyer RL. Single-cell force spectroscopy of bacteria enabled by naturally derived proteins. Langmuir. 2014;30:4019-25. https://doi.org/10.1021/la404673q.

47. Formosa-Dague C, Speziale P, Foster TJ, Geoghegan JA, Dufrêne YF. Zinc-dependent mechanical properties of Staphylococcus aureus biofilm-forming surface protein SasG. Proc Natl Acad Sci U S A. 2016;113:410-5. https://doi.org/10.1073/pnas.1519265113.

48. Dufrêne YF. Sticky microbes: forces in microbial cell adhesion. Trends Microbiol. 2015;23:376-82. https://doi.org/10.1016/j.tim. 2015.01.011.

49. Herman P, El-Kirat-Chatel S, Beaussart A, Geoghegan JA, Foster TJ, Dufrêne YF. The binding force of the staphylococcal adhesin SdrG is remarkably strong. Mol Microbiol. 2014;93:356-68. https://doi.org/10.1111/mmi.12663.

50. Neu TR, Lawrence JR. Advanced techniques for in situ analysis of the biofilm matrix (structure, composition, dynamics) by means of laser scanning microscopy. Methods Mol Biol Microb Biofilms. 2014;1147:43-64. https://doi.org/10.1007/978-1-4939-0467-9 4.

51. Romero-Lastra P, Sánchez MC, Llama-Palacios A, Figuero E, Herrera D, Sanz M. Gene expression of Porphyromonas gingivalis ATCC 33277 when growing in an in vitro multispecies biofilm. PLoS One. 2019;14:e0221234. https://doi.org/10.1371/journal. pone. 0221234 .

52. Karygianni L, Hellwig E, Al-Ahmad A. Multiplex fluorescence in situ hybridization (M-FISH) and confocal laser scanning microscopy (CLSM) to analyze multispecies oral biofilms. In: Walker JM, Editor. Methods Mol. Biol. Microb. Biofilms, Humana Press Inc.; 2014, p. 65-72. https://doi.org/10.1007/978-1-4939-0467-9 5 .

53. Neu T, Kuhlicke U. Fluorescence lectin bar-coding of glycoconjugates in the extracellular matrix of biofilm and bioaggregate forming microorganisms. Microorganisms. 2017;5: 5. https://doi.org/10.3390/microorganisms5010005.

54. Zippel B, Neu TR. Characterization of glycoconjugates of extracellular polymeric substances in tufa-associated biofilms by using fluorescence lectin-binding analysis. Appl Environ Microbiol. 2011;77:505-16. https://doi.org/10.1128/AEM.01660-10.

55. Turonova H, Neu TR, Ulbrich P, Pazlarova J, Tresse O. The biofilm matrix of Campylobacter jejuni determined by fluorescence lectin-binding analysis. Biofouling. 2016;32:597-608. https://doi.org/10.1080/08927014.2016.1169402.

56. Sportelli MC, Tütüncü E, Picca RA, Valentini M, Valentini A, Kranz C, et al. Inhibiting P. fluorescens biofilms with fluoropolymer-embedded silver nanoparticles: an in-situ spectroscopic study. Sci Rep. 2017;7:11870. https://doi.org/10.1038/ s41598-017-12088-x.

57. Stenclova P, Freisinger S, Barth H, Kromka A, Mizaikoff B. Cyclic changes in the amide bands within Escherichia coli biofilms monitored using real-time infrared attenuated total reflection spectroscopy (IR-ATR). Appl Spectrosc. 2019;73:424-32. https://doi.org/10.1177/0003702819829081.

58. Cui L, Zhang DD, Yang K, Zhang X, Zhu YG. Perspective on surface-enhanced Raman spectroscopic investigation of microbial world. Anal Chem. 2019;91:15345-54. https://doi.org/10.1021/ acs.analchem.9b03996.

59. Virdis B, Harnisch F, Batstone DJ, Rabaey K, Donose BC. Noninvasive characterization of electrochemically active microbial biofilms using confocal Raman microscopy. Energy Environ Sci. 2012;5:7017-24. https://doi.org/10.1039/c2ee03374g.

60. Quilès F, Humbert F, Delille A. Analysis of changes in attenuated total reflection FTIR fingerprints of Pseudomonas fluorescens 
from planktonic state to nascent biofilm state. Spectrochim Acta Part A Mol Biomol Spectrosc. 2010;75:610-6. https://doi.org/10. 1016/j.saa.2009.11.026.

61. Czerwińska-Główka D, Krukiewicz K. A journey in the complex interactions between electrochemistry and bacteriology: from electroactivity to electromodulation of bacterial biofilms. Bioelectrochemistry. 2020;131:107401. https://doi.org/10.1016/j. bioelechem.2019.107401.

62. Xu S, Barrozo A, Tender LM, Krylov AI, El-Naggar MY. Multiheme cytochrome mediated redox conduction through Shewanella oneidensis MR-1 cells. J Am Chem Soc. 2018;140: 10085-9. https://doi.org/10.1021/jacs.8b05104.

63. Snider RM, Strycharz-Glaven SM, Tsoi SD, Erickson JS, Tender LM. Long-range electron transport in Geobacter sulfurreducens biofilms is redox gradient-driven. Proc Natl Acad Sci U S A. 2012;109:15467-72. https://doi.org/10.1073/pnas.1209829109.

64. Simcox LJ, Pereira RPA, Wellington EMH, Macpherson JV. Boron doped diamond as a low biofouling material in aquatic environments: assessment of Pseudomonas aeruginosa biofilm formation. ACS Appl Mater Interfaces. 2019;11:25024-33. https://doi.org/10.1021/acsami.9b07245.

65. Ciani I, Schulze H, Corrigan DK, Henihan G, Giraud G, Terry JG, et al. Development of immunosensors for direct detection of three wound infection biomarkers at point of care using electrochemical impedance spectroscopy. Biosens Bioelectron. 2012;31:413-8. https://doi.org/10.1016/j.bios.2011.11.004.

66. Peter Revsbech N. Analysis of microbial communities with electrochemical microsensors and microscale biosensors. In: Leadbetter J, Editor. Methods in Enzymology., Elsevier Inc; 2005, p. 147-66. https://doi.org/10.1016/S0076-6879(05)970092.

67. Babauta JT, Nguyen HD, Beyenal H. Redox and pH microenvironments within Shewanella oneidensis MR-1 biofilms reveal an electron transfer mechanism. Environ Sci Technol. 2011;45: 6654-60. https://doi.org/10.1021/es200865u.

68. De Beer D, Schramm A, Santegoeds CM, Kuhl M. A nitrite microsensor for profiling environmental biofilms. Appl Environ Microbiol. 1997;63:973-7. https://doi.org/10.1128/AEM.63.3. 973-977.1997.

69. Schreiber F, Polerecky L, de Beer D. Nitric oxide microsensor for high spatial resolution measurements in biofilms and sediments. Anal Chem. 2008;80:1152-8. https://doi.org/10.1021/ac071563x.

70. Babauta JT, Nguyen HD, Istanbullu O, Beyenal H. Microscale gradients of oxygen, hydrogen peroxide, and $\mathrm{pH}$ in freshwater cathodic biofilms. ChemSusChem. 2013;6:1252-61. https://doi. org/10.1002/cssc. 201300019.

71. Bellin DL, Sakhtah H, Zhang Y, Price-Whelan A, Dietrich LEP, Shepard KL. Electrochemical camera chip for simultaneous imaging of multiple metabolites in biofilms. Nat Commun. 2016;7: 10535. https://doi.org/10.1038/ncomms 10535 .

72. Darch SE, Koley D. Quantifying microbial chatter: scanning electrochemical microscopy as a tool to study interactions in biofilms. Proc R Soc A Math Phys Eng Sci. 2018;474:20180405. https:// doi.org/10.1098/rspa.2018.0405.

73. Wessel AK, Hmelo L, Parsek MR, Whiteley M. Going local: technologies for exploring bacterial microenvironments. Nat Rev Microbiol. 2013;11:337-48. https://doi.org/10.1038/ nrmicro3010.

74. Mirkin MV, Bard AJ, editors. Scanning electrochemical microscopy. 2nd ed. Boca Raton: CRC; 2012.

75. Polcari D, Dauphin-Ducharme P, Mauzeroll J. Scanning electrochemical microscopy: a comprehensive review of experimental parameters from 1989 to 2015. Chem Rev. 2016;116:13234-78. https://doi.org/10.1021/acs.chemrev.6b00067.
76. Izquierdo J, Knittel P, Kranz C. Scanning electrochemical microscopy: an analytical perspective. Anal Bioanal Chem. 2018;410: 307-24. https://doi.org/10.1007/s00216-017-0742-7.

77. Katemann BB, Schuhmann W. Fabrication and characterization of needle-type Pt-disk nanoelectrodes. Electroanalysis. 2002;14:22 8. https://doi.org/10.1002/1521-4109(200201)14:1<22::AIDELAN22 $>3.0 . C O ; 2-F$

78. Sun P, Mirkin MV. Kinetics of electron-transfer reactions at nanoelectrodes. Anal Chem. 2006;78:6526-34. https://doi.org/ 10.1021/ac060924q.

79. Cai C, Liu B, Mirkin MV, Frank HA, Rusling JF. Scanning electrochemical microscopy of living cells. 3. Rhodobacter sphaeroides. Anal Chem. 2002;74:114-9. https://doi.org/10. 1021/ac010945e.

80. Stoodley P, Sauer K, Davies DG, Costerton JW. Biofilms as complex differentiated communities. Annu Rev Microbiol. 2002;56: 187-209. https://doi.org/10.1146/annurev.micro.56.012302. 160705.

81. Liu X, Ramsey MM, Chen X, Koley D, Whiteley M, Bard AJ. Real-time mapping of a hydrogen peroxide concentration profile across a polymicrobial bacterial biofilm using scanning electrochemical microscopy. Proc Natl Acad Sci U S A. 2011;108:266873. https://doi.org/10.1073/pnas.1018391108.

82. Holt KB, Bard AJ. Interaction of silver(I) ions with the respiratory chain of Escherichia coli: an electrochemical and scanning electrochemical microscopy study of the antimicrobial mechanism of micromolar Ag. Biochemistry. 2005;44:13214-23. https://doi. org/10.1021/bi0508542.

83. Fulaz S, Hiebner D, Barros CHN, Devlin H, Vitale S, Quinn L, et al. Ratiometric imaging of the in situ $\mathrm{pH}$ distribution of biofilms by use of fluorescent mesoporous silica nanosensors. ACS Appl Mater Interfaces. 2019;11:32679-88. https://doi.org/10.1021/ acsami.9b09978.

84. Hwang G, Liu Y, Kim D, Sun V, Aviles-Reyes A, Kajfasz JK, et al. Simultaneous spatiotemporal mapping of in situ $\mathrm{pH}$ and bacterial activity within an intact 3D microcolony structure. Sci Rep. 2016;6:1-11. https://doi.org/10.1038/srep32841.

85. Horrocks BR, Mirkin MV, Pierce DT, Bard AJ, Nagy G, Toth K Ion-selective potentiometric microscopy. Anal Chem. 1993;65: 1213-24. https://doi.org/10.1021/ac00057a019.

86. Wipf DO, Ge F, Spaine TW, Baur JE. Microscopic measurement of $\mathrm{pH}$ with iridium oxide microelectrodes. Anal Chem. 2000;72: 4921-7. https://doi.org/10.1021/ac000383j.

87. Lindfors T, Ivaska A. $\mathrm{pH}$ sensitivity of polyaniline and its substituted derivatives. J Electroanal Chem. 2002;531:43-52. https://doi.org/10.1016/S0022-0728(02)01005-7.

88. Joshi VS, Sheet PS, Cullin N, Kreth J, Koley D. Real-time metabolic interactions between two bacterial species using a carbonbased $\mathrm{pH}$ microsensor as a scanning electrochemical microscopy probe. Anal Chem. 2017;89:11044-52. https://doi.org/10.1021/ acs.analchem.7b03050.

89. Carano M, Holt KB, Bard AJ. Scanning electrochemical microscopy. 49. Gas-phase scanning electrochemical microscopy measurements with a Clark oxygen ultramicroelectrode. Anal Chem. 2003;75:5071-9. https://doi.org/10.1021/ac034546q.

90. Nagamine K, Kaya T, Yasukawa T, Shiku H, Matsue T. Application of microbial chip for amperometric detection of metabolic alteration in bacteria. Sensors Actuators B Chem. 2005;108:676-82. https://doi.org/10.1016/j.snb.2004.10.050.

91. Matsui N, Kaya T, Nagamine K, Yasukawa T, Shiku H, Matsue T. Electrochemical mutagen screening using microbial chip. Biosens Bioelectron. 2006;21:1202-9. https://doi.org/10.1016/j.bios. 2005.05.004.

92. Connell JL, Kim J, Shear JB, Bard AJ, Whiteley M. Real-time monitoring of quorum sensing in 3D-printed bacterial aggregates using scanning electrochemical microscopy. Proc Natl Acad Sci U 
S A. 2014;111:18255-60. https://doi.org/10.1073/pnas. 1421211111.

93. Koley D, Ramsey MM, Bard AJ, Whiteley M. Discovery of a biofilm electrocline using real-time 3D metabolite analysis. Proc Natl Acad Sci U S A. 2011;108:19996-20001. https://doi.org/10. 1073/pnas.1117298108.

94. Abucayon E, Ke N, Cornut R, Patelunas A, Miller D, Nishiguchi MK, et al. Investigating catalase activity through hydrogen peroxide decomposition by bacteria biofilms in real time using scanning electrochemical microscopy. Anal Chem. 2014;86:498-505. https://doi.org/10.1021/ac402475m.

95. Joshi VS, Kreth J, Koley D. Pt-decorated MWCNTs-ionic liquid composite-based hydrogen peroxide sensor to study microbial metabolism using scanning electrochemical microscopy. Anal Chem. 2017;89:7709-18. https://doi.org/10.1021/acs.analchem. $7 \mathrm{~b} 01677$.

96. Kaya T, Numai D, Nagamine K, Aoyagi S, Shiku H, Matsue T. Respiration activity of Escherichia coli entrapped in a cone-shaped microwell and cylindrical micropore monitored by scanning electrochemical microscopy (SECM). Analyst. 2004;129:529-34. https://doi.org/10.1039/b316582e.

97. Zhan D, Fan FRF, Bard AJ. The Kv channel blocker 4aminopyridine enhances Ag+ uptake: a scanning electrochemical microscopy study of single living cells. Proc Natl Acad Sci U S A. 2008;105:12118-22. https://doi.org/10.1073/pnas.0805286105.

98. Nagamine K, Onodera S, Kurihara A, Yasukawa T, Shiku H, Asano R, et al. Electrochemical screening of recombinant protein solubility in Escherichia coli using scanning electrochemical microscopy (SECM). Biotechnol Bioeng. 2007;96:1008-13. https:// doi.org/10.1002/bit.21173.

99. Kaya T, Nishizawa M, Yasukawa T, Nishiguchi M, Onouchi T, Matsue T. A microbial chip combined with scanning electrochemical microscopy. Biotechnol Bioeng. 2001;76:391-4. https://doi. org/10.1002/bit.10085.

100. Erttmann SF, Gekara NO. Hydrogen peroxide release by bacteria suppresses inflammasome-dependent innate immunity. Nat Commun. 2019;10:1-13. https://doi.org/10.1038/s41467-01911169-x.

101. Gilliland SE. Enzymatic determination of residual hydrogen peroxide in milk. J Dairy Sci. 1969;52:321-4. https://doi.org/10. 3168/jds.S0022-0302(69)86554-9.

102. Emerson D, Peteu S, Worden RM. A catalase microbiosensor for detecting hydrogen peroxide. Biotechnol Tech. 1996;10:673-8. https://doi.org/10.1007/BF00168478.

103. Karyakin AA, Karyakina EE. Electroanalytical applications of Prussian blue and its analogs. Russ Chem Bull. 2001;50:1811-7. https://doi.org/10.1023/A:1014373811238.

104. Li Y, Sella C, Lemaître F, GuilleCollignon M, Thouin L, Amatore C. Highly sensitive platinum-black coated platinum electrodes for electrochemical detection of hydrogen peroxide and nitrite in microchannel. Electroanalysis. 2013;25:895-902. https://doi.org/ 10.1002/elan.201200456.

105. Meirelles LA, Newman DK. Both toxic and beneficial effects of pyocyanin contribute to the lifecycle of Pseudomonas aeruginosa. Mol Microbiol. 2018;110:995-1010. https://doi.org/10.1111/ mmi.14132.

106. Ummadi JG, Downs CJ, Joshi VS, Ferracane JL, Koley D. Carbon-based solid-state calcium ion-selective microelectrode and scanning electrochemical microscopy: a quantitative study of $\mathrm{pH}$-dependent release of calcium ions from bioactive glass. Anal Chem. 2016;88:3218-26. https://doi.org/10.1021/acs. analchem.5b04614.

107. Harris D, Ummadi JG, Thurber AR, Allau Y, Verba C, Colwell F, et al. Real-time monitoring of calcification process by Sporosarcina pasteurii biofilm. Analyst. 2016;141:2887-95. https://doi.org/10.1039/C6AN00007J.
108. Jayathilake NM, Koley D. Glucose microsensor with covalently immobilized glucose oxidase for probing bacterial glucose uptake by scanning electrochemical microscopy. Anal Chem. 2020;92: 3589-97. https://doi.org/10.1021/acs.analchem.9b04284.

109. Rudolph D, Bates D, DiChristina TJ, Mizaikoff B, Kranz C. Detection of metal-reducing enzyme complexes by scanning electrochemical microscopy. Electroanalysis. 2016;28:2459-65. https://doi.org/10.1002/elan.201600333.

110. Kim C, Kim J, Park HY, Park HJ, Lee JH, Kim CK, et al. Furanone derivatives as quorum-sensing antagonists of Pseudomonas aeruginosa. Appl Microbiol Biotechnol. 2008;80: 37-47. https://doi.org/10.1007/s00253-008-1474-6.

111. Lijuan C, Xing Y, Minxi W, Wenkai L, Le D. Development of an aptamer-ampicillin conjugate for treating biofilms. Biochem Biophys Res Commun. 2017;483:847-54. https://doi.org/10. 1016/j.bbrc.2017.01.016.

112. Pecchielan G, Battistel D, Daniele S. Scanning electrochemical microscopy and voltammetric investigation of silver nanoparticles embedded within a Nafion membrane. ChemElectroChem. 2016;3:2297-304. https://doi.org/10.1002/celc.201600483.

113. Kite P, Eastwood K, Sugden S, Percival SL. Use of in vivogenerated biofilms from hemodialysis catheters to test the efficacy of a novel antimicrobial catheter lock for biofilm eradication in vitro. J Clin Microbiol. 2004;42:3073-6. https://doi.org/10. 1128/JCM.42.7.3073-3076.2004.

114. Casalinuovo IA, Sorge R, Bonelli G, Di Francesco P. Evaluation of the antifungal effect of EDTA, a metal chelator agent, on Candida albicans biofilm. Eur Rev Med Pharmacol Sci. 2017;21:1413-20.

115. Fan F-RF, Bard AJ. Chemical, electrochemical, gravimetric, and microscopic studies on antimicrobial silver films. J Phys Chem B. 2002;106:279-87. https://doi.org/10.1021/jp012548d.

116. Aponso S, Ummadi JG, Davis H, Ferracane J, Koley D. A chemical approach to optimizing bioactive glass dental composites. J Dent Res. 2019;98:194-9. https://doi.org/10.1177/ 0022034518809086.

117. Sim W, Barnard RT, Blaskovich MAT, Ziora ZM. Antimicrobial silver in medicinal and consumer applications: a patent review of the past decade (2007-2017). Antibiotics. 2018;7:1-15. https:// doi.org/10.3390/antibiotics7040093.

118. Durán N, Durán M, de Jesus MB, Seabra AB, Fávaro WJ, Nakazato G. Silver nanoparticles: a new view on mechanistic aspects on antimicrobial activity. Nanomedicine: Nanotechnology, Biology and Medicine. 2016;12:789-99. https://doi.org/10.1016/j.nano.2015.11.016.

119. Sportelli MC, Picca RA, Cioffi N. Recent advances in the synthesis and characterization of nano-antimicrobials. TrAC - Trends Anal Chem. 2016;84:131-8. https://doi.org/10.1016/j.trac.2016. 05.002 .

120. Battistel D, Baldi F, Gallo M, Faleri C, Daniele S. Characterisation of biosynthesised silver nanoparticles by scanning electrochemical microscopy (SECM) and voltammetry. Talanta. 2015;132:294 300. https://doi.org/10.1016/j.talanta.2014.09.023.

121. Conzuelo F, Schulte A, Schuhmann W. Biological imaging with scanning electrochemical microscopy. Proc R Soc A Math Phys Eng Sci. 2018;474:20180409. https://doi.org/10.1098/rspa.2018. 0409.

122. Hu Z, Jin J, Abruña HD, Houston PL, Hay AG, Ghiorse WC, et al. Spatial distributions of copper in microbial biofilms by scanning electrochemical microscopy. Environ Sci Technol. 2007;41:93641. https://doi.org/10.1021/es061293k.

123. Moreira R, Schütz MK, Libert M, Tribollet B, Vivier V. Influence of hydrogen-oxidizing bacteria on the corrosion of low carbon steel: local electrochemical investigations. Bioelectrochemistry. 2014;97:69-75. https://doi.org/10.1016/j.bioelechem.2013.10. 003. 
124. Takahashi Y, Shiku H, Murata T, Yasukawa T, Matsue T. Transfected single-cell imaging by scanning electrochemical optical microscopy with shear force feedback regulation. Anal Chem. 2009;81:9674-81. https://doi.org/10.1021/ac901796r.

125. Salamifar SE, Lai RY. Use of combined scanning electrochemical and fluorescence microscopy for detection of reactive oxygen species in prostate cancer cells. Anal Chem. 2013;85:9417-21. https://doi.org/10.1021/ac402367f.

126. Takahashi Y, Shevchuk AI, Novak P, Zhang Y, Ebejer N, Macpherson JV, et al. Multifunctional nanoprobes for nanoscale chemical imaging and localized chemical delivery at surfaces and interfaces. Angew Chem Int Ed. 2011;50:9638-42. https://doi. org/10.1002/anie.201102796.

127. Nault L, Taofifenua C, Anne A, Chovin A, Demaille C, BesongNdika J, et al. Electrochemical atomic force microscopy imaging of redox-immunomarked proteins on native potyviruses: from subparticle to single-protein resolution. ACS Nano. 2015;9: 4911-24. https://doi.org/10.1021/acsnano.5b00952.

128. Kueng A, Kranz C, Lugstein A, Bertagnolli E, Mizaikoff B. Integrated AFM-SECM in tapping mode: simultaneous topographical and electrochemical imaging of enzyme activity. Angew Chem Int Ed. 2003;42:3238-40. https://doi.org/10.1002/ anie.200351111.

129. Cannan S, Douglas Macklam I, Unwin PR. Three-dimensional imaging of proton gradients at microelectrode surfaces using confocal laser scanning microscopy. Electrochem Commun. 2002;4: 886-92. https://doi.org/10.1016/S1388-2481(02)00482-4.

130. Mariscal A, Lopez-Gigosos RM, Carnero-Varo M, FernandezCrehuet J. Fluorescent assay based on resazurin for detection of activity of disinfectants against bacterial biofilm. Appl Microbiol Biotechnol. 2009;82:773-83. https://doi.org/10.1007/s00253009-1879-x.

131. Guerret-Legras L, Audibert JF, Dubacheva GV, Miomandre F. Combined scanning electrochemical and fluorescence microscopies using a tetrazine as a single redox and luminescent (electrofluorochromic) probe. Chem Sci. 2018;9:5897-905. https://doi.org/10.1039/c8sc01814f.

132. Guerret-Legras L, Audibert JF, Ojeda IMG, Dubacheva GV, Miomandre F. Combined SECM-fluorescence microscopy using a water-soluble electrofluorochromic dye as the redox mediator.
Electrochim Acta. 2019;305:370-7. https://doi.org/10.1016/j. electacta.2019.03.069.

133. Takahashi Y, Shevchuk AI, Novak P, Murakami Y, Shiku H, Korchev YE, et al. Simultaneous noncontact topography and electrochemical imaging by SECM/SICM featuring ion current feedback regulation. J Am Chem Soc. 2010;132:10118-26. https:// doi.org/10.1021/ja1029478

134. Page A, Kang M, Armitstead A, Perry D, Unwin PR. Quantitative visualization of molecular delivery and uptake at living cells with self-referencing scanning ion conductance microscopy-scanning electrochemical microscopy. Anal Chem. 2017;89:3021-8. https://doi.org/10.1021/acs.analchem.6b04629.

135. Anne A, Cambril E, Chovin A, Demaille C. Touching surfaceattached molecules with a microelectrode: mapping the distribution of redox-labeled macromolecules by electrochemical-atomic force microscopy. Anal Chem. 2010;82:6353-62. https://doi.org/ 10.1021/ac1012464

136. Knittel P, Zhang H, Kranz C, Wallace GG, Higgins MJ. Probing the PEDOT:PSS/cell interface with conductive colloidal probe AFM-SECM. Nanoscale. 2016;8:4475-81. https://doi.org/10. 1039/c5nr07155k.

137. Daboss S, Lin J, Godejohann M, Kranz C. Redox switchable polydopamine-modified AFM-SECM probes: a novel probe for electrochemical force spectroscopy. Anal Chem. 2020;92(12): 8404-13 acs.analchem.0c00995. https://doi.org/10.1021/acs. analchem.0c00995.

138. Keevil CW. The physico-chemistry of biofilm-mediated pitting corrosion of copper pipe supplying potable water. Water Sci Technol. 2004;49:91-8. https://doi.org/10.2166/wst.2004.0096.

139. Barforoush JM, McDonald TD, Desai TA, Widrig D, Bayer C, Brown MK, et al. Intelligent scanning electrochemical microscopy tip and substrate control utilizing fuzzy logic. Electrochim Acta. 2016;190:713-9. https://doi.org/10.1016/j.electacta.2015.12.112.

140. Stein HS, Gregoire JM. Progress and prospects for accelerating materials science with automated and autonomous workflows. Chem Sci. 2019;10:9640-9. https://doi.org/10.1039/c9sc03766g.

Publisher's note Springer Nature remains neutral with regard to jurisdictional claims in published maps and institutional affiliations. 